\title{
Exploration of Customers' Expectation of, and Perception of the Service they Receive from Mobile Phone Providers
}

\author{
Article by Theophine Ugochukwu Achugbu \\ MBA, Texila American University, Ireland \\ Email: theoachugbu@gmail.com
}

\begin{abstract}
PURPOSE- The purpose of this paper is to explore customers' expectation of and perception of the service they receive from mobile phone providers and to identify service quality gaps as experienced by customers in the mobile telecommunications industry in Ireland.

Design/Methodology/Approach- The nine modified dimensions of SERVQUAL, namely tangibles, reliability, responsiveness, assurance, empathy, network aspect, convenience, loyalty and pricing were used in this research work to measure customers' expectations and perceptions from mobile providers. This was done by using the entire households in Esker woods, Lucan, County Dublin, Ireland, meaning that there was no sampling but rather the whole population of 128 households served as respondents. The researcher therefore employed census method.

Findings- The overall service quality as perceived by customers in Ireland was above average with $56.09 \%$ of the respondents while $22.67 \%$ were dissatisfied leaving $21.24 \%$ of respondents undecided. This was based on the nine SERVQUAL dimensions. The research findings revealed that though more than half of the respondents were satisfied with services they received; it's very interesting to note that most of these respondents were satisfied with services received under six dimensions. These were tangibles, reliability, responsiveness, assurance, empathy and convenience. On the other hand, a very high percentage of respondents judging from individual dimensions of loyalty, network aspect and pricing were dissatisfied with the perceived service quality. The highest service quality gap was reported with the added dimension of loyalty, network aspect and pricing while the lowest service quality gap was reported with tangibles.

Practical Implications- Data representing customers expectations and perceptions with mobile providers in delivering quality have been used to identify in terms of quality gaps areas that need improvement. Mobile phone providers in Ireland should focus on providing superior network services and affordable prices to customers.

Originality/Value- It should be noted that since most quality features in the SERVQUAL scale have relationship with customer handling, the researcher has incorporated and investigated further the added four dimensions of network aspect, service convenience, loyalty and pricing for their contribution to the overall service quality of mobile providers.
\end{abstract}

Keywords- Service quality, customer satisfaction, customer loyalty, SERVQUAL, Mobile phone providers in Ireland

\section{Introduction}

\section{Background of the Research}

As mobility becomes an increasing prevalent force shaping the lifestyles of consumers, the market for the technologies and devices accompanying this trend also improves at fast pace (Hande, Kimiloglu et al., 2010). Any product that offers individuals the ability to work, communicate or entertain themselves in a location-free manner captures immediate acceptance and diffuses rapidly into consumers' lives. Mobile phones are one of the most conspicuous examples of such innovations achieving a large penetration rate in many markets (Hande, Kimiloglu et al., 2010). The speed and magnitude of mobile phone adoption is a 
South American Journal of Management

Special Edition 2016

recent worldwide phenomenon akin to that of the television in the mid-20th century (Katz and Aakhus, 2002; Rice and katz, 2003.

Prior to 1990, the mobile phone was a rare and expensive technology with an adoption level too low for the charts to even register. During the 1990s, mobile phone adoption exploded with subscriptions reaching a half billion worldwide and well into the billions in the following decade. In fact those who do not use mobile phones are now in the minority in many countries (International Telecommunication Union, 2005). Telephones, especially mobile telephones provide the basic connection for social interaction between individuals and the linkages both within and among nations. Global interaction is made easier (Haque, A., Khatibi, A. and Raquib, A 2007). Deutsch (1953) mentioned this as "a web of nations". The mobile telecommunication system has become the electronic infrastructure for transmitting all kinds of information, for instance, voice, data, graphics, video, music (Beard and Hartmann 1999).

In a competitive market, service providers are expected to compete on both price and quality of service and it is equally necessary for the service providers to meet the customers' requirements and expectations in price and service quality (Melody, W.H. 2001). According to RNCOS (2008), increased demand for mobile entertainment and technically advanced applications for business have infused growth in the mobile industry worldwide. Intense competition among mobile phone companies triggering significant price reductions also contributed to the worldwide boom in the industry. Kollmann, (2000) equally highlighted a link between price and customer perception.

Mobile telecommunications industry in Ireland has not seen much research in the sector though the outlook is positive hence the researcher's undiluted interest in the sector. It is pertinent to note that data gathered from Mintel report 2003 estimates the expenditure by consumers on mobile phone services in 2002 was $€ 1,546$ million in Ireland. Expenditure on mobile services represents $1.4 \%$ of GDP in Ireland. The overall telecommunications sector in Ireland accounts for an estimated 3\% of GDP or $€ 3.3$ billion per annum. Mintel estimates that there were 3.08 million mobile phone subscribers in Ireland by the end of 2002. This puts the penetration level at $79 \%$.

Given the financial and other constraints, it is essential that expectations are properly understood and measured from the customer's perspective in order to identify any gap (s) in service quality. Conceptually, the service quality process can be examined in terms of gap between expectations and perceptions on the part of management, employees and customers (Ghobadian et al., 1994) This information then assist the decision-makers in identifying most effective ways of closing service quality gaps and of prioritizing which gap(s) to focus- a critical decision given scarce resources. Among the tools of measuring service quality that focus external perspective, SERVQUAL developed by Parasuraman et al. (1988), seems to be useful and widely adopted by researchers (Hoffman and Bateson, 2001).

In this research work, the researcher will use SERVQUAL dimensions to measure service quality gap.

Today, there are five main companies known as service providers in Ireland, namely: Vodafone; Meteor; 3-Network; E-Mobile; and Tesco Mobile (ComReg: Quarterly Report 2015). Telefonica-O2 was acquired by 3 -network in 2013. Service quality is essential and important for a mobile telecommunication service provider company to ensure the quality service for establishing and maintaining loyal and profitable customer (Leinsen and Vance 2001).

\section{Interest in the Subject and Suitability of Researcher}

The researcher's childhood passion for telecommunication grows to infinity. His determination of linking the world in one global village through telecommunication is deeprooted on the fact that in the world of today the dependence on mobile telecommunications is ever growing and continues to evolve. Arguably a mobile phone has become an essential consumer durable and is no longer perceived as a luxury item. One other major reason for his 
unalloyed interest in this sector is that the researcher due to the ever increasing challenges faced by customers, he wants to make a critical investigation to find appropriate measures to tackle these challenges. The researcher worked in an international telecommunications company and most of these challenges mentioned above are encountered in his work place hence his frantic effort to ameliorate the problems faced by customers.

The views of customers concerning mobile network services include many specific complaints, about the obscurity of the tariffs and their high level, but there are also widespread concerns about the poor quality of service (QoS), difficulties in termination of contracts, failure to provide contracted services-sometimes with long outages, inaccuracy in billing, the lack of customer care and, for businesses, the absence of service level agreements (SLA's) (Ewan, Sutherland, 2007).

By comparison with the fixed telephony network, the performance of cellular networks is less certain and the quality poorer. Indeed, anecdotal evidence suggests that the quality of mobile calls helped to prepare customers for voice over internet protocol VoIP (Ewan, Sutherland 2007). According to him, there is no shortage of evidence of complaints about the poor quality of service provided by mobile operators, indeed a pattern of disappointment seems commonplace and in some cases the networks are not being built to deliver a high level of quality for all the users all of the time. Disappointment also reflects incorrect perceptions caused by advertising that goes beyond what can or often what will be realised by the network engineers and by the support systems. Operators face significant challenges in aligning engineering realities with marketing vision and customer expectations (Ewan, Sutherland. 2007).

It is as a result of the above problems that many countries have developed "horizontal" legislation to protect consumers in all markets, supported by agencies and consumer groups, magazines and television programmes, supplemented by special regulations for telecommunications. (Ewan, Sutherland. 2007).In other countries there is specific consumer protection legislation for telecommunications. In Ireland where this research focuses, there are AskComReg.ie and Callcosts.ie, both provided by the Commission for Communications Regulation (ComReg) to supplement its own more formal website.

In the long run, the most important single factor affecting a business unit's performance is the quality of its products and services, relative to those of competitors. A quality edge according to Zeithaml, V.A., Parasuraman, A. and Berry, L.L (1990) boosts performance in the short run through increased profits and in the long term, superior and/or improving relative service quality is the more effective way for a business to grow.

Although the Irish economy remains in recession and this is having a devastating impact in terms of employment, consumer spending and disposable income levels, the economic outlook remains bright (Mintel report 2010). According to some observers the Irish economy has the potential to grow in the short term; the Economic and Social Research Institute (ESRI) estimates GDP growth for 2010 of $0.25 \%$ and of $2.75 \%$ in 2011 .

Customers are always at the epicentre of most business strategies and the need to add extra value to every cent spent by a customer cannot be overemphasised. Considering the impact of the recent global financial crisis and the associated increased competition in mobile phone industry, this research is being carried out to explore customer's expectation and perception of the service they receive from mobile phone providers in Ireland.

The research was also conducted to answer the research question: Why is there gap in service quality and what are those factors that affect customers' perceived service quality?

The objectives of the research are:

i. $\quad$ To explore the differences between expected and perceived service as experienced by users and to identify the service quality gaps using the modified SERVQUAL dimensions

ii. To critically examine the effect of customer satisfaction on loyalty and retention

iii. To examine the relationship between customer's cultural value orientations on their perceived service quality. 
South American Journal of Management

Special Edition 2016

\section{Structure of the Research}

This research paper will have six chapters with each chapter addressing a main issue in the research.

Chapter one will provide a general introduction to the research. It will also identify the research problem and objectives. This chapter will equally highlight the general background of the research in the context of the perceived service quality in the mobile telephony.

Chapter two will focus on literature reviews highlighting three areas: customer satisfaction loyalty and retention; customer behaviour intentions and cultural differences and an overview of mobile telecommunications industry in Ireland.

Chapter three will look at the research methods \& methodology and ethical issues.

In Chapter four, the research findings will be analysed and interpreted.

Chapter five will draw on all the conclusions from the research; followed by the researcher's reflections on learning in chapter six.

\section{Limitations of Research}

The researcher discovered some limitations during this research process which might limit the scope of this research. Firstly, the researcher found that most of the secondary data was not updated coupled with the time constraint as the researcher had to apply some rush in order to meet up with the deadline. The researcher had to make repeated (though approved) visits to many respondents in order to monitor the filling of questionnaires and this invariably ate into researcher's limited time and this might affect the validity of the research.

\section{Major Contributions of the Research}

This research will among other contributions enable those in the top echelon of management, the decision makers in the mobile telecommunications industry in Ireland to have a thorough understanding of why there are service quality gaps as experienced by customers. As most businesses operate under the going concern principles, it is vitally important for management to attract and retain customers. One major way of achieving this is by closing the service quality gap which this research work had dealt copiously with.

\section{Literature Review}

In the past few decades, a lot of attention has been focused on service quality especially from researchers and practitioners due to its strong impact on business performance, customer satisfaction, customer loyalty and profitability (Santouridis, I. and Trivellas, P. 2010). The importance of service quality cannot be overemphasised hence, Headley, D. and Miller, S. (1994) argued that service quality relies on a simple but powerful discrepancy paradigm: initial service expectations must be met or exceeded by perceived outcomes of the service experience. Although some authors like Parasuraman, Zeithaml and Berry, (1985, 1988); Carman, (1990) agree that service quality is an abstract concept, difficult to define and measure, some definitions have been made. Traditionally service quality has been defined as the difference between customer expectations and perceptions of service (Gronroos, 1984; Parasuraman et al., 1988, 1991).

\section{The concept of service quality}

Services are deeds, processes, and performances provided or coproduced by one entity or person for another entity or person (Zeithaml, V.A. et al., 2009).

Quality is defined as conformance to requirements, not elegance (Crosby 1979)

Customer Expectations are beliefs about service delivery that serve as standards or reference points against which performance is judged (Zeithaml, V.A et al., 2009)

Customer Perception is defined as the entire process by which an individual becomes aware of the environment and interprets it so that it will fit into his or her frame of reference (Walters et al., 1989). 
The sources of customer expectations are marketer-controlled factors (such as pricing, advertising, sales promises, as well as factors that the marketer has limited ability to affect (innate personal needs, word-of-mouth communications, and competitive offerings). In a perfect world, expectations and perceptions would be identical: customers would perceive that they have received what they thought they would and should. In practice these concepts are often, even usually, separated by some distance (Zeithaml, V.A et al., 2009).

Service Quality, as perceived by customers, can be defined as the extent of discrepancy between customers' expectations or desires and their perceptions (Parasuraman, A., Zeithaml, V.A. and Berry, L. 1990). Closing the gap between what customers expect and what they perceive is critical to delivering quality service and forms the basis for the gaps model/"gap analysis". The customer gap is the difference between customer expectations and perceptions (Zeithaml, V.A et al., 2009) (see figure 2.1 below)

\section{THE CUSTOMER GAP}

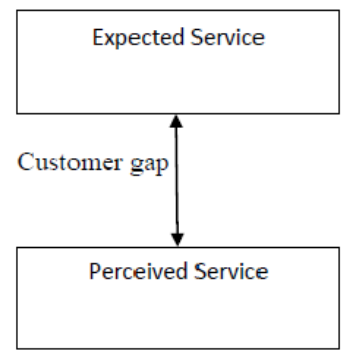

Figure 2.1: The customer gap

Source: Zeithaml, V.A., Bitner, M.J. and Gremler, D.D (2009)

The gaps model positions the key concepts, strategies and decisions in delivering quality service in a manner that begins with the customer and builds the organisation's tasks around what is needed to close the gap between customer expectations and perceptions (Zeithaml, V.A. and Parasuraman, A. 2004) see figure 2.2

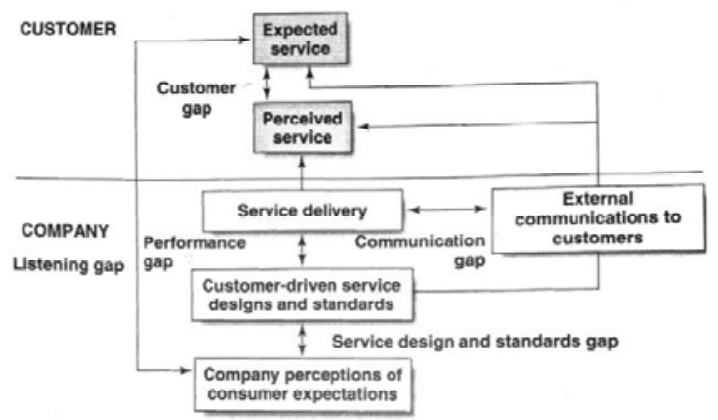

Figure 1.2: Gaps model of service quality

Source: Adapted from Zeithaml, V.A., Bitner, M.J. and Gremler, D.D., Service marketing: Integrating Customer Focus across the Firm, McGraw-Hill, 2009.

The figure above shows that the central focus (top half) of the gaps model is the customer gap, and to close this all-important customer gap the gaps model suggests that four other gaps-the provider gaps-need to be closed (Zeithaml, V.A et al., 2009).

Gap 1: Not knowing what customers expect (or the Listening gap). This gap 1 is the difference between customer expectations of service and company, particularly management, understanding of those expectations. When people with authority and responsibility for setting priorities do not fully understand customers' service expectations, they may trigger a chain of bad decisions and sub-optimal resource allocations that result in perceptions of poor service quality (Zeithaml, V.A. and Parasuraman, A. 2004). 
Gap 2: The Wrong Service Quality Designs and Standards. The repeated challenge in service companies is the difficulty of translating customers' expectations into service quality specifications. Provider gap 2 therefore reflects the difference between company understanding of customer expectations and development of customer-driven service designs and standards. When managers, frontline employees, behind-the-scenes support staff and other people involved are not working with the same concepts of the new service, based on customer needs and expectations, service design will likely be poor (Shostack 1992).

Gap 3: Not Delivering to Service Standards (The Service Performance Gap). Provider gap 3 is the discrepancy between development of customer-driven service standards and actual service performance by company employees. (Zeithaml, Berry and Parasuraman 1988). Narrowing gap 3 by ensuring that all the resources (people, systems and technology) needed to achieve the standards are in place reduces the customer gap (Zeithaml, V.A and Parasuraman, A. (2004).

Gap 4: Not Matching Performance to Promise (The Communication Gap). Provider gap 4 is the difference between service delivery and the service provider's external communications. Promises made by a service company through its media advertising, sales force, and other communications may potentially raise customer expectations and serve as the standard against which customers assess service quality (Zeithaml, Berry, and Parasuraman 1988). The discrepancy between actual and promised service (i.e. in form of broken promises) therefore has an adverse effect on the customer gap.

\section{Customer satisfaction, loyalty and retention}

In recent years, manufacturers and service providers have made quality of service their priority in today's customer-centred era. Delivering service quality has been recognised so importantly that businesses not only require it for success but in some cases, for survival. Thus achieving and maintaining customer-perceived service quality is regarded as essential strategy for the successful provision of overall customer satisfaction and customer retention (Taylor and Baker, 1994; Reichheld and Sasser, 1990). Therefore, measuring perceived service quality is considered to be fundamental in developing a customer-oriented strategy that ensures the long-term survival of the firm (MacStravic, 1997). Some proponents of service quality state that quality can be defined only by customers and occurs when an organisation supplies goods or services to a specification that satisfies the customer's need (Negi, R. 2009). As more and more firms are searching for new ways to achieve, retain, upgrade and leverage competitive advantages, given the fact that customers are becoming more demanding, competition is getting more intense and technology is changing more rapidly (Wang, Y. and Hing-Po Lo. 2002).

Satisfaction is the consumer's fulfilment response. It is a judgement that a product or service feature, or the product or service itself, provides a pleasurable level of consumptionrelated fulfilment (Oliver, R.L. 1997). Zeithaml, V.A. et al., (2009) interpreted this definition to mean that satisfaction is the customer's evaluation of a product or service in terms of whether that product or service has met the customer's needs and expectations. According to the Greek Philosopher, Epictetus, "What concerns me is not the way things are, but rather the way people think things are"

The evolution in customer satisfaction measurement between the 1950's and 1990's is an interesting one. Hardly anyone in the mid-1970s spoke much about customer service, and this was in part the legacy of the Second World War (Szwarc, P. 2005). Reconstruction of consumer economies in the western world was paramount during the 1950's and by the 1960 's, the period of consumer restraint and rationing was long forgotten as economies expanded and consumers once again had money to spend on new goods and services. In this period, most companies gained new customers fairly easily as they launched waves of new and better products and services. Szwarc, P. (2005) argued that it's not surprising that organisations did not focus as much time and attention on customer service and the concept of customer satisfaction. 
In a bid to save money, leading management thinkers in the 1980's, such as William E. Rothschild of the U.S. General Electric Corporation, noticed that a strategic advantage could be gained if customer service was treated as a strategic business tool. Some companies embarked upon after-sales programmes and these companies (mostly home appliances and allied companies) started looking at ways to improve their 'product breakdown' service and market research was one of the business tools they used. Market research techniques were developed to examine customer reactions to the way companies 'corrected' the faults that had emerged and how quickly they could be corrected. Mystery shopping-where trained individuals would pose as customers and check out whether certain operational procedures were being adhered to in establishments they were monitoring, was one such tool.

By the early 1990s, when the world economy went into another major recession, two concepts emerged that changed how companies viewed, and managed, customer service. These concepts were the balanced scorecard and customer relationship management (CRM). Robert S. Kaplan (professor of accounting at Harvard Business School) and David P Norton (president of Nolan, Norton and Company, a Massachusetts-based information technology consulting firm) created the balanced scorecard in 1991. What Kaplan and Norton provided was a set of measures that gave management a fast and comprehensive view of an organisation by complementing the financial and operational measures with two new perspectives, a measure of customer satisfaction and a measure of the way an organisation 'learns'- an innovation and improvement perspective (Kaplan and Norton, 1991).

\section{Determinants of customer satisfaction}

Customer satisfaction is influenced by specific product or service features, perceptions of product and service quality \& price, customer's mood or emotional state and situational factors such as family member opinions (Zeithaml, V.A. et al 2009)

Product and Service Features- Oliver, R.L. (1997) argued that customer satisfaction with a product or service is influenced significantly by the customer's evaluation of product or service features. For hospitality industry, e.g. resort hotel, important features might include the pool area, access to golf facilities, restaurants, room comfort and privacy, helpfulness and courtesy of staff, room price, etc. According to Ostrom, A. and Iacobucci, D. (1995), research has shown that customers of services will make trade-offs among different service features (e.g., price level versus quality versus friendliness of personnel versus level of customization), depending on the type of service being evaluated and the criticality of the service.

Emotions of Consumer- Customers' emotions can affect their perceptions of satisfaction with products and services (Oliver, R.L. 1997). These emotions can be stable, pre-existing emotions-e.g. mood state or life satisfaction. He stressed that when people are at a very happy stage in their lives (such as when they are on vacation), and their good, happy mood and positive frame of mind have influenced how they feel about the services they experience. Alternatively, when people are in their bad mood, their negative feelings may carry over into how they respond to services, causing them to overreact or respond negatively to any little problem.

Attributions for Service Success or Failure- Attributions- the perceived causes of events, influence perceptions of satisfaction (Folkes, V.S. 1988). When customers have been surprised by an outcome (the service is either much better or much worse than expected), they tend to look for the reasons, and their assessments of the reasons can influence their satisfaction. (Hubbert, A.R. 1995)

Perceptions of Equity or Fairness- Customer satisfaction is also influenced by perceptions of equity and fairness. Customers ask themselves: Have I been treated fairly compared with other customers? Did other customers get better treatment, better prices, or better quality service? Did I pay a fair price for the service? Was I treated well in exchange for what I paid and the effort I expended? Notions of fairness are central to customers' 
South American Journal of Management

Special Edition 2016

perceptions of satisfaction with products and services, particularly in service recovery situations (Clemmer, E.C. and Schneider, B. 1996)

Family Members and Co-workers- In addition to product and service features and one's own individual feelings and beliefs, consumer satisfaction is often influenced by other people (Fournier, S. and Mick, D.G. 1999). For example, satisfaction with a family vacation trip is a dynamic phenomenon, influenced by the reactions and emotions of individual family members over the duration of the vacation. What family members express in terms of satisfaction or dissatisfaction with the trip will be influenced by stories that are retold among the family and selective memories of the events.

Harris and Harrington, (2000) pointed out that customer satisfaction can be attained by companies, which have understood their customer's needs and make every effort to provide services in an effective and efficient manner. Consequently, service quality is clearly linked to customer satisfaction.

\section{Customer loyalty \& retention}

Customer loyalty is of critical importance for companies and especially for those operating in service industries. In such settings, service providers compete with companies very similar to themselves so that they often respond by employing customer retention strategies (Egan, 2004, p. 133). Thus, the challenge they have to face is to retain existing customers by winning their loyalty. Higher levels of customer satisfaction can lead to a reduction of the perceived benefits of alternative suppliers and hence to higher repurchase intentions (Anderson and Sullivan, 1993). In order to further emphasize this point, Anderson and Srinivasan (2003) claim that "a dissatisfied customer is more likely to search for information on alternatives and more likely to yield to competitor overtures than is a satisfied customer".

McCarthy D. (1997) argued that many companies responded to this by cutting prices, as they mistakenly believed that price equated to loyalty and these companies believed that the lower the price, the more likely it was that customers would stay with the company. Paul Szwarc (2005) argued that what many companies had failed to realise was that customer satisfaction was not necessarily a reflection that customers were feeling positive about their organisations; rather it was that they were not feeling negative about them. In other words, they had no reason to defect.

After a thorough examination by many companies during the recession of the early 1990s of the performance of their marketing and sales expenditure, they discovered that it cost a lot more to acquire new customers than to retain existing ones, and that they also cost a lot more to manage (Paul Szwarc, 2005). McCarthy, D (1997) argues that during this early 1990s, it was not very difficult to find news headlines reporting growing customer dissatisfaction, and he believes that it is partly because organisations view customer satisfaction as a cost rather than an investment, and in particular, fail to invest in people at the front line. He asserts that satisfied customers are not something you can buy, and that their loyalty has to be earned. It builds with every single touch point with an organisation hence companies need a stable and highly motivated workforce to be able to deliver a good service, he argues.

The customer is the judge of service quality, Szwarc, P. (2005) and even where service is provided by a machine, e.g. a cash machine can only deliver the services for which it is programmed. If it is out of cash, and a customer wants to use it to get cash, the customer will seek another machine, which may be a competitor's machine. If this machine delivers customers the cash they want, they may be tempted to use it again in the future. As Horovitz, (1990: 6) puts it, 'Services exist in human experience and for service industries, service consists of two dimensions: basic features sought by the customer and the service experience at the time of consumption'. The risk of losing the customer increases as customer frustration grows, and as choice of supplier increases and the ease of switching supplier becomes easier (Paul Szwarc, 2005).

'Loyalty' is about a customer's intention or predisposition to buy, but 'retention' is the actual act of buying again (Michael Johnson and Anders Gustafsson, 2000: 7). 'Satisfied' 
customers and 'loyal customers both contribute to company profitability in different ways. Satisfied customers are more likely to 'promote' the company, because satisfaction is something people will talk about. Loyal customers however are more profitable because they are more likely to buy additional products, often without shopping around for the best price (Paul Szwarc, 2005). He argued that dissatisfied customers are a real cost to a company, because they criticize the company to others- and that research has shown that dissatisfied customers are likely to tell more people about their dissatisfaction than satisfied customers tell about why they are satisfied. It is worthy of note that not everybody would agree with the concept that loyalty is about repurchasing. Dr Hofmeyr, J (2004) suggested that there is a difference between loyalty and commitment. He argues that a 'loyal' customer might be someone who repurchases products and services but is not necessarily committed to the organisation and that he or she might be repurchasing out of habit or for some other reason. A committed customer has a stronger emotional bond to the organisation, and so is less likely to buy elsewhere, and more likely to be tolerant if things go slightly wrong.

As management became more interested in customer service and loyalty, new research techniques and models were developed (such as Simalto and SERVQUAL). There are different business models and theories that have been developed over the last couple of decades to measure and improve customer satisfaction, loyalty and company profitability. Some, such as Six Sigma, help organisations improve customer satisfaction, loyalty and profitability by concentrating on improving internal processes or operations through rigorous data gathering and analysis of those areas important to the customer. Some organisations use business tools such as the balanced scorecard and the balanced service chain. These ensure that the organisation's strategic plan is understood and implemented by all employees. The plans are built on the premise that if the organisation focuses on delivering the type of quality service desired by loyal customers and providing real management and systems support to front-line employees, profits will follow (Szwarc, P. 2005).

There has been a shift from a transaction to a relationship focus in marketing. Customers become partners and the firm must make long- term commitments to maintaining those relationships with quality, service, and innovation (Webster Jr, F.E. 1992)

Relationship marketing essentially represents a paradigm shift within marketing-away from an acquisitions/transaction focus toward a retention/relationship focus (Gronroos, C. (1990). Relationship marketing (or relationship management) is a philosophy of doing business, a strategic orientation, which focuses on keeping and improving relationships with current customers rather than on acquiring new customers. This philosophy assumes that many consumers and business customers prefer to have an ongoing relationship with one organisation than to switch continually among providers in their search for value. (Zeithaml, V.A., Bitner, M. and Gremler, D.D. 2009) They suggested that it is usually much cheaper to keep a current customer than to attract a new one.

Berry, L.L. and Parasuraman, A. (1991) argued that firms frequently focus on attracting customers (the "First act") but then pay little attention to what they should do to keep them (the "Second act"). When James 1. Schorr, then executive vice president of marketing at Holiday Inns, Knisely, G. (1979) was interviewed, he referred to the "bucket theory of marketing". He stressed that marketing can be thought of as a big bucket: it is what the sales, advertising, and promotion programs do that pours business into the top of the bucket (see figure 2.3) 


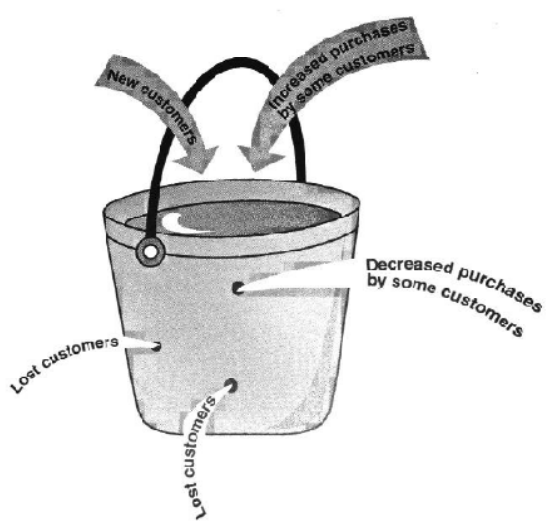

Figure 2.3: Bucket theory of marketing

Source: Zeithaml, V.A., Bitner, M.J. and Gremler, D.D (2009)

$\mathrm{He}$ argued that as long as these programs are effective, the bucket stays full, but however, there exists one major problem which is that "there is a hole in the bucket". When an organisation's business is running well, and delivering on its promises, the hole is small and few customers are leaving, but when the operation is weak and customers are not satisfied with what they get- and therefore the relationship is weak- people start falling out of the bucket through the holes faster than they can be poured in through the top. Historically, marketers have been more concerned with acquisition of customers Zeithaml, V.A., Bitner, M. and Gremler, D.D. (2009), so a shift to a relationship strategy often represents changes in mind-set, organisational culture, and employee reward system. For example, the sales incentive systems in many organisations are set up to reward bringing in new customers. There are often fewer (or no) rewards for retaining the already existing customers. Thus, even when people see the logic of customer retention, the existing organisational systems may not support its implementation.

Customer defection, or "customer churn", is widespread in service businesses. Customer defection is costly to companies because new customers must replace lost customers, and replacement comes at a high cost. Getting new customers is expensive; it involves advertising, promotion, and sales costs as well as start-up operating expenses. New customers are often unprofitable for a period of time after acquisition. Capturing customers from other companies is also an expensive proposition: a greater degree of service improvement is necessary to make a customer switch from a competitor than to retain a current customer (Zeithaml, V.A., Bitner, M. and Gremler, D.D. 2009).

In general, the longer a customer remains with the company, the more profitable the relationship is for the organisation: Served correctly, customers generate increasingly more profits each year they stay with a company. Across a wide range of businesses, the pattern is the same, i.e. the longer a company keeps a customer, the more money it stands to make (Reichheld, F. and Sasser, E. 1990)

\section{Customer behaviour intentions and cultural differences}

Although "research examining the effect of customer value and customer satisfaction on behaviour intentions has received very limited attention in the marketing literature" Athanassopoulos, (2000), Rust and Oliver's (1994) call for research did not go unanswered. Bagozzi's (2002) model suggests that initial service evaluation leads to an emotional reaction that in turn, drives behaviour. And it has been suggested that customer value leads to favourable behaviour intentions (Chang and Wildt, 1994; Cronin et al., 1997; Gale, 1994). Similarly, customer satisfaction drives favourable behaviour intentions too (Anderson et al., 1994; Swanson and Kelley, 2001). For some time, it has been understood that different value orientations cause variations in preferences for products and brands. Values of both 
consumers and marketers are defined by their culture, hence the need to understand the value concept and culture cannot be overemphasised (De Mooij, 2004).

A value is defined as an enduring belief that one mode of conduct or end-state of existence is preferable to an opposing mode of conduct or end-state of existence. A value system is an enduring organisation of beliefs concerning preferable modes of conduct or end-states of existence along a continuum of relative importance (Rockeach, M.1973). People of different countries have different value orientations that cause variation in preferences of products and brands (De Mooij, M. 2004).

Consumer behaviour can be defined as the study of the processes involved when individuals or groups select, purchase, use, or dispose of products, services, ideas, or experiences to satisfy needs and desires. In other words, consumer behaviour is viewed as a process that includes the issues that influence the consumer before, during, and after a purchase (De Mooij, M. 2004). He stressed that culture must be integrated in the various components of human behaviour for a clear understanding of the influence of culture on consumer behaviour De Mooij, M. (2004) concluded. Acknowledging that behaviours are difficult to predict and understand, it has been suggested that a person will generally act in accordance with predisposing intentions (Ajzen and Fishbein 1980). An intent to behave is a result of experience with a service or information deemed relevant by the consumer about that service. This predisposition or attitude is seen as a determining factor in a consumer's behaviour toward the offering as future need arises. Some of the possible behaviours exhibited by the consumer are: repeat purchase, complimenting, complaining, switching providers and opting not to use any service at all.

The model in figure 2.4 below structures the cultural components of the person in terms of consumer attributes and processes, and the cultural components of behaviour in consumer behaviour domains.

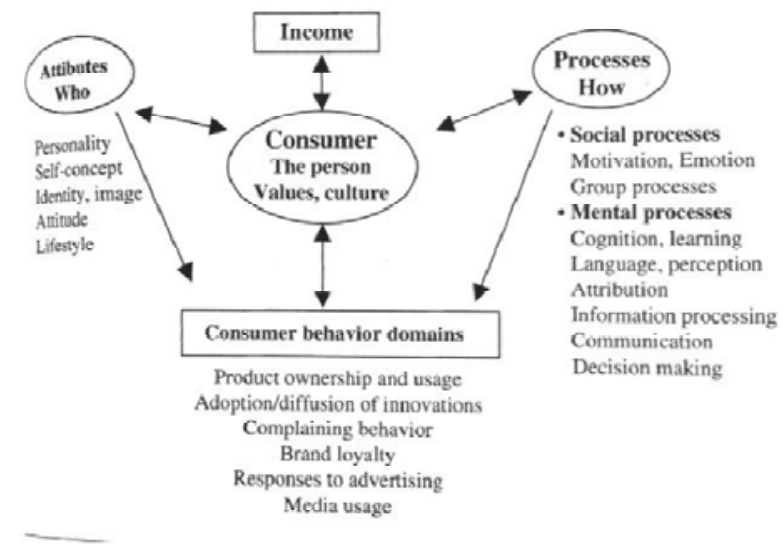

Figure 2.4: Framework of cross cultural consumer behaviour

Source: Adapted from De Mooij, Marieke, 2004

Personality is the sum of qualities and characteristics of being a person. Generally, a person is viewed as an "independent self-contained, autonomous entity who comprises a unique configuration of internal attributes (e.g., traits, abilities, motives and values) and who behaves primarily as a consequence of these internal attributes" (De Mooij, M. 2004). According to Kotler, P (1994), each person has a distinct personality that will influence his or her buying behaviour. De Mooij, M (2004) argues that western psychology is rooted in individualism while on the other hand, in the collectivistic model of the self, persons are fundamentally interdependent with one another. In this collectivistic model, the self cannot be separated from others and the surrounding social context. This concept of self, he stressed, is characteristic of Asia, much of South America, and Africa and went further to say that 
behaviour is a consequence of being responsive to the others with whom one is interdependent and behaviour originates in relationships.

The cross-cultural psychologists Markus, H.R. and Kitayama, S. (1991) state that the self or the identity is critical because it is the psychological locus of cultural effects. It functions as a mediating, orienting and interpretative framework that will systematically bias how members of a given socio-cultural group will think, feel and act. The self is shaped by the cultural context, and in turn it strongly influences social behaviour through a variety of avenues including an individual's perceptions, evaluations, and values (Singelis, Theodore M. 2000).

Psychologists, as highlighted by De Mooij, M. (2004) agree that the self-concept plays a central role in behaviour and psychological processes. Diaz-Loving, Rolando (1998) argues that it consists of whatever individuals consider to be theirs, including their body, family, possessions, moods, emotions, conscience, attitudes, values, traits and social position. A major distinction according to Roland, A. (1988) is between the independent self of individualistic cultures and the interdependent self of collectivistic cultures. In individualistic cultures, focus is on individual autonomy.

The sense of self which develops as a child grows up and establishes him or herself as an independent individual (De Mooij, M. 2004). Identity is the idea one has about oneself, one's characteristic properties, one's own body, and the values one considers important. Image on the other hand is how others see and judge a person (Antonides, G. and Van Raaij, W.F. 1998). Identity among collectivists is defined by relationships and group memberships, whereas individualists base identity on what they own and their experiences. Identity also is one's capacity to fulfil expectations e.g. when persons are asked what their identity is, they can categorise themselves in terms of desirable values, as members of social groups (e.g., a father, a student), or by personality traits, for example "ambitious," "cheerful" (De Mooij, M. 2004).

Consumer behaviourists view an attitude as a lasting, general evaluation of people (including oneself), objects, advertisements, or issues (Solomon, M. et al., 1999). A global attitude concerns an overall attitude toward a product or brand, without separate attributes playing a role. A differentiated attitude is a combination of beliefs and evaluations. The beliefs concern the perceived characteristics of products and the evaluative components can be connected with values (Antonides and Van Raaij, 1998. P. 20). They argued that people's attitudes are guided by their values, which make them culture-bound, attitudes drive behaviour, but behaviour also drives attitudes.

The Western assumption is that attitudes lead people to behave in a fairly consistent way towards similar objects (Kotler, P. 1994. P. 188). The aspect of attitude being consistent is specific of individualistic cultures. In collectivistic cultures attitudes may vary along with the context in which they operate. Attitudes have affective and cognitive components. The affective component includes sensations, feelings, and emotions one experiences in response to an attitude object. The cognitive component includes various attributes and functions of the object (Cervellon, Marie-Cecile and Dube, laurette, 2002).

For measuring advertising effectiveness, the attitude to the advertisement (Aad) as argued by De Mooij, M. (2004), tends to be measured, which in turn is used as an indication of buying intention. This practice, he stressed is logical in individualistic cultures where individuals want consistency between their attitudes and behaviours. In collectivistic cultures where situational factors can influence the various elements of attitude and behaviour, the practice may not work the same way. Western consumer behaviour theory states that under certain conditions the behaviour of consumers can be predicted from their attitudes towards products, services and brands (Antonides and Van Raaij, 1998. P. 202).

Lifestyle is described in terms of shared values or tastes as reflected in consumption patterns. Personal characteristics are viewed as the "raw" ingredients to develop a unique lifestyle (Grunert, Klaus G. et al., 1997). Lifestyle, argues De-Mooij, M (2004) may be a useful within-country criterion; it is less useful for defining segments across cultures because 
lifestyles are country-specific. He stressed that increasing evidence is found that culture overrides lifestyle.

Marketing theorists have often viewed culture as one of the underlying determinants in consumers' decision-making processes (Blackwell, Miniard, and Engel, 2000). The significance of culture in understanding human behaviour (of which consumer behaviour is a part) is that it extends our understanding of the extent to which people are more than just chemistry, physiology, or a set of biological drives and instincts. The implication is that although all customers may be biologically similar, their views of the world, what they value, and how they act differ according to their cultural backgrounds (Loudon, D.L and Della Bitta, A.J 1993). In cross-cultural understanding of consumer behaviour, more and more companies have adopted a global outlook in which the world becomes their market. For example, numerous major corporations, such as Coca-Cola, Hoover, IBM, Pfizer, and Gillette, receive over half of their earnings from foreign operations, while many others also have significant international markets. Such situations require the marketer's appreciation both of cultural differences among international markets and of their influence on consumer behaviour (Loudon, D.L and Della Bitta, A.J 1993).

Although there is a lack of consensus among scholars about the definitions and operations of culture, (Kroeber and Kluckhohn, 1952; Hofstede's (1980, 1991) seminar work on five dimensions of culture is the most commonly used framework in consumer research. These five dimensions include individualism versus collectivism (IDV-COL), power distance (PDI), masculinity versus feminity (MAS-FEM), uncertainty avoidance (UAI). Collectivism is defined as how individuals perceive their relationships with other groups in society, while individualism emphasises independence and personal preferences and needs (Dutta-Bergman and Wells, 2002). In collectivistic cultures, priorities are given to harmony, conformity, and close relationships within groups (De Mooij, 2004). Power distance is defined as "the extent to which less powerful members of a society accept and expect that power is distributed unequally" (De Mooij and Hofstede, 2002, p.63). In large PDI cultures, individuals are expected to behave according to their place in the society (De Mooij, 2004). Emphases are placed on authority, respect, and inequality. In masculine cultures, the dominant values are success and achievement, while those in feminine cultures are quality of life and caring for the weaker. Uncertainty avoidance refers to how individuals react to uncertainty and ambiguity in their life.

Hofstede (1997, p.5), defines culture as "the collective programming of the mind which distinguishes the members of one group from another". More individualistic and weak uncertainty avoidance cultures are characterised by higher consumer innovativeness and higher risk tolerance, whereas strong uncertainty avoidance is related to resistance to new innovations and security seeking (Kivija at al., 2007). People from different countries and cultures make different assumptions about what information is the most important (Zahedi et al., 2001).

\section{An overview of mobile telecommunications industry in Ireland}

Generally, the history of mobile phones charts the development of devices which connect wirelessly to the public switched telephone network (PSTN). The PSTN is the network of the world's public circuit-switched telephone networks. It consists of telephone lines, fibre optic cables, microwave transmission links, cellular networks, communications satellites, and undersea telephone cables, all inter-connected by switching centres, thus allowing any telephone in the world to communicate with any other. Originally, a network of fixed-line analogue telephone systems, the PSTN is now almost entirely digital in its core and includes mobile as well as fixed telephones (Gow, G.A. and Smith, R.K. 2006; Fluhr, Z. and Nussbaum, E. 1973)

Up until the end of 1999, the penetration level of mobile phones in Ireland was relatively low. This is due to cost of the technology at the time. During the period 1995-99 inclusive, GDP growth each year was at record levels in Ireland, as the country went through the 
economic period known as the 'Celtic Tiger'. During this time, growth in PDI matched or exceeded GDP growth, and both of these can be closely related to the sharp decline in unemployment. Economic growth peaked in 2000, and this is also the year in which record mobile phone sales were recorded in Ireland. During 2000 over 1.4 million mobile phone subscribers were added to the user base, representing $46 \%$ of the current user base i.e. in 2000 (MINTEL 2003)

In Ireland, near universal access to the mobile phone as a technological device has been achieved. Unlike the personal computer (PC) and broadband, the mobile phone has been widely adopted and deeply embedded into the lives of people in all strata of society. Elaborate communication and social practices have evolved around use of the mobile phone: In how people communicate with each other, conduct their lives, relationships and business, and consume information and media services (Cawley, A and Hynes, D. 2010).

The contribution that telecommunication makes to GDP is significant, with the telecommunications services market representing 3\% of GDP in Ireland based on 2001 figures. This would include the contribution made by mobile communication services, but not by retail sales of accessories and equipment (MINTEL 2003)

The changes to the mobile phones market include rapid increases in penetration levels, changes to ownership and branding of mobile network operators, the awarding of third generation (3G) licences, and subsequently (4G) licences in 2013, development of new services and advancement in technology. Arguably a mobile phone has become an essential consumer durable and is no longer perceived as a luxury item. This is a direct result of mobile phones becoming accessible at mass-market price levels. It is also related to the fact that economic and employment growth in recent years has raised the quality of living, impacting on the buying power of consumers.

In Ireland, the telecommunication sector is regulated by the Commission for Telecommunications Regulation (ComReg), which was established in December 2002. Prior to this, regulation was the responsibility of Office of Director of Telecommunications Regulation (ODTR). The (ODTR) was established in 1997 and, having assumed responsibility for regulating the postal sector in 2000, its functions for both sectors were transferred to the Commission for Communications Regulation (ComReg) in 2002.

ComReg (incorporating its predecessor the ODTR) was Ireland's first independent economic sectoral regulator and was created to oversee the introduction and development of competition in the then newly-liberalised communications markets. Its mandate was clear and remains so today - to create a competitive market place, protect and inform consumers, and promote the internal market. In doing so, ComReg must also ensure the efficient use of Ireland's radio frequency spectrum and promote the development of the postal sector and in particular the availability of a universal postal service within, to and from the State at an affordable price for the benefit of all users.

The Callcosts website, www.callcosts.ie, is a free, up-to-date, easy to use and independent website that covers most telephone, mobile and broadband plans available in Ireland. It is run by ComReg. The Callcosts website helps people to compare the cost of different plans available for their home phone, mobile and broadband services. Many providers offer different types of plans and sometimes it is hard to know if the plan you are on is the best one for you. Mintel (2005)

The Irish market has a number of operators that are designated as having significant market presence (SMP) and thus there is a need for regulation. In the mobile telecommunications market both Vodafone and $\mathrm{O} 2$ were designated as having SMP in 2012. At present, the major mobile phone companies operating in Ireland are: Vodafone, Meteor, 3-Network, E-Mobile, and Tesco Mobile. Others are Postfone Mobile, 48-Months Mobile, More Mobile, Blueface Mobile, and Lyca Mobile. (www.askcomreg.ie). The Regulator ensures, among other things, that licensed operators provide high-quality and price-competitive services to end-users. The regulator also has responsibility for the management of the radio spectrum. 
Vodafone Group Plc is one of the world's leading mobile telecommunications companies. Established in the UK in 1984, it now has a significant presence in Europe, the Middle East, Africa, Asia Pacific and the US (Mintel 2010). In Ireland its mobile subscriber base now numbers 2.35 million and just over two thirds of those customers use prepaid services. The company according to Mintel 2010 has a total of 2.35 million customers in Ireland, which includes just under 200,000 fixed line and fixed line broadband subscribers.

Formed in 2001, O2 became part of Telefonica in 2006 (Telefónica-O2), Europe group which comprises integrated fixed/mobile businesses in the UK, Ireland, Germany, the Czech Republic and Slovakia - all of which use 'O2' as their consumer brand. In October 2007, Telefonica-O2 established the Tesco MVNO service joint venture business in the UK and Ireland. Telefonica-O2 has 72 stores in Ireland as at 2010 (Mintel 2010) but was acquired by 3-Network in 2013.

Meteor Mobile Communications according to Mintel (2010) was established in 2001 after being awarded Ireland's third mobile licence. It is a wholly owned subsidiary of Eircom Group plc. Meteor's network covers over $98 \%$ of the Irish population. It has 40 stores throughout Ireland including regional offices in Limerick, Galway and Cork.

The operator 3 is a subsidiary of Hong Kong-based conglomerate Hutchison Whampoa. As befits its name, the operator focuses on $3 \mathrm{G}$ technology. The company entered the Irish market in 2005 and runs its Irish and UK operations through Hutchison 3G UK Limited and Hutchison $3 \mathrm{G}$ Ireland Limited. It uses a combination of its own outlets and concessions in expanding its presence on the high street. It has 32 shops in Ireland (Mintel 2010).

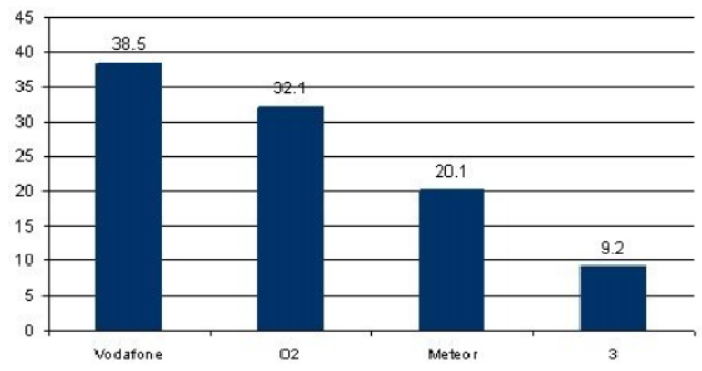

Figure 2.5: Market share of mobile phone operators (voice \& data) Ireland 2010

Source: ComReg/Mintel (2010)

See appendix 12 for List of Mobile Network Operators in Ireland (Technology Used and Ownership)

There are various methods available to segment the mobile phones market in Ireland Mintel (2000). Mobile network operators market different services to meet different customer requirements. Broadly, the main packages consist of either:

- Pre-paid (Pay-as-you-go) phone packages

- Contract (Bill Pay) phone packages

These packages are broadly aimed at either personal or business users. Beyond this market segmentation there are other key segments, for example, text messaging and downloads. Business and personal users are the two main types of user in the mobile market.

Both personal and business users are becoming more technically savvy. As the mobile market becomes further saturated Mintel (2005), networks and manufacturers have turned their attention to improving and furthering technology to extend the appeal of their products.

The progress of mobile technology has become a major market driver, with many people embracing mobile services such as $3 \mathrm{G} \& 4 \mathrm{G}$ Internet and email access and Bluetooth. Such customers are often high earners, with significant spending power. These consumers are generally conscious of updating and upgrading their phones regularly, often on an annual basis. The sector seeks to both cross-sell and up-sell to such customers, by offering more advanced services, accessories, complimentary and substitution goods and newer and 
improved talk plans. With such customers, retention by the network provider is of paramount importance (Mintel, 2005)

According to Mintel, 2005 report, Pre-paid customers account for a significantly higher percentage share of all mobile phone revenues than post-paid contract users. See Figure 2.6 below:

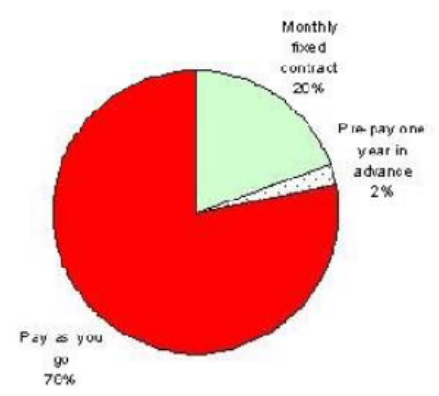

Figure 2.6: Prepay/contract comparison for adult aged 15+

Taken from the TGI survey of around 3,000 adults in Ireland Source: RoI TGI, BMRB, 2004/Mintel

Pre-paid subscribers accounted for $74 \%$ of the Irish market in 2004. Pre-paid phones allow users to budget for their mobile phones more easily. These users don't have the monthly worry of a large mobile phone bill because they can purchase call credit in advance of their calls. Pre-paid mobile phones are therefore a more attractive option to lower income groups, parents who are purchasing a phone for their child or for people who only use their mobile phone on a limited basis (Mintel 2005)

Pre-paid mobile phone users generally need to pay for their phone handset, in contrast to mobile subscription users who often receive free handsets (most times, depending on the make \& model of the handset and tariffs) on registration. However, with many contract mobile phone users availing of annual free upgrades, many older models are provided as "hand-me-downs" to family and friends who use them in conjunction with a pre-paid package. The price plans for pre-paid packages tend to be more expensive on a per minute basis, with monthly subscription prices tending to be around $75 \%$ of the price paid by pay-asyou-go customers (MINTEL 2005). Differences between pay-as-you-go subscribers and contract subscribers may result from a number of issues, including barriers preventing some from becoming post-paid customers. Opening a post-paid monthly contract account requires credit checks, bank accounts and direct debit payment facilities, and these are often not available to many mobile phone users.

It is clear that the monthly fixed contract is a more attractive option to businesses where the inconvenience of topping up is a huge drawback, compared to receiving a monthly invoice which business processes are more likely to accommodate. For heavy users, like business customers, post-pay is also likely to be a much more attractive option since it provides better value for money. Business customers in Ireland, MINTEL (2005), drive the monthly subscription mobile phones segment. Estimates indicate that personal users account for only $6 \%$ of mobile monthly subscriptions, and these would tend to be in the middle-income bracket.

This sector (bill pay) seems to have suffered as most personal users have opted for the budgetary control offered by pre-paid services. The post-paid segment in Ireland was worth $€ 445.4$ million in 2004 , almost $€ 15$ million less than its value in 2000 . The decline in the value of the segment may be explained by the better value deals offered by providers to the prepay customers, with an abundance of free minutes and text message bundles available. Although this trend (i.e. with prepay still having an upper hand, continued in 2011 in terms of the percentage share of the market though the gap is not as staggering as it was in 2005 in most mobile providers. See figure 2.7 below: 


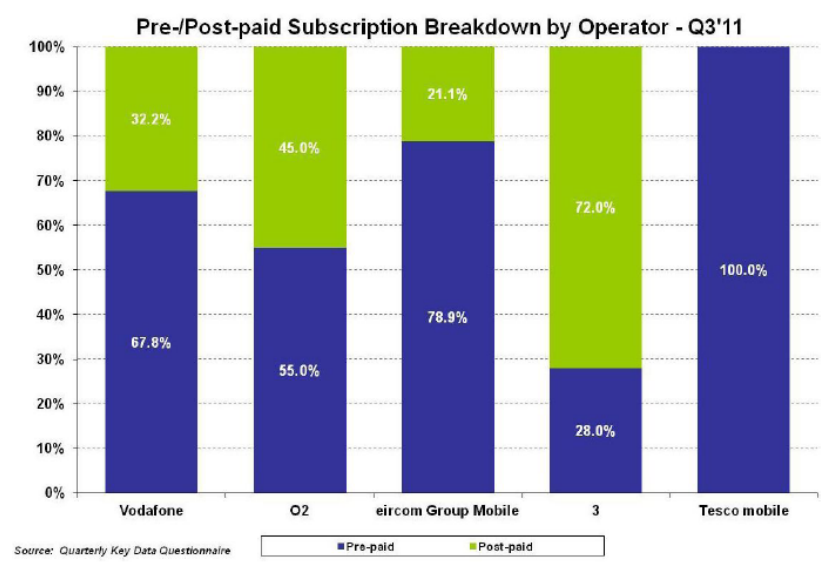

Figure 2.7: Prepay/postpay subscription breakdown

The mobile phone market has experienced heavy sales losses across the board, as a result of economic recession in Ireland, market saturation and product cannibalisation. While the outlook is positive for mobile technology in general, this will be reliant on how well manufacturers and retailers adapt, and in particular, utilise the key tools of innovation and marketing. The technologically mature consumer now uses mobile technology in very different ways, and this is continuing to evolve. In terms of its potential to bring virtual and digital marketing to the consumer there is significant scope for mobile technology to be further developed by manufacturers and marketers alike (Mintel 2010)

Interest in technology that offers improved convenience and functionality for the consumer is strong. According to 2009 TGI data, half of respondents in Ireland claim that they try to keep up with developments in technology, and almost half look to the internet for information when they need it. Smart phones are seen as the way forward for maintaining revenue growth for the mobile phone sector. Smart phones already contain a calendar/organiser, photograph functionality payment functionality and business cards, these devices now have the potential to act as a replacement for the traditional wallet for some users. (Mintel 2010)

In the Irish mobile phone market, the need to improve network coverage has been reechoed several times by customers. According to a survey conducted exclusively for this report by Toluna in April 2010, the majority of respondents in Ireland quoted poor network coverage as being the issue which frustrates them most when using mobile technologies. Given the expected growth in use of mobile broadband, this issue is likely to continue to aggravate consumers until full and reliable network coverage is attained (Mintel 2010). According to the report, lack of reception is a key frustration for consumers when it comes to using mobile phones and generally mobile technology in Ireland. The report on the other hand highlighted on the frustrations of customers about the high prices of phones and tariffs (price plans) and also stressed that their demand for lower prices on mobile phone voice charges will continue to drive down market value if not checked.

The industry has been subject to much negative publicity in both 2009 and 2010, regarding the charges for roaming. As a result, consumers are more wary of incurring these charges and instead may choose to leave their phone at home, or else not use it at all, when travelling. Mobile operators prior to 2009/2010 agreed to reduce roaming rates following a vote by the European Parliament in April 2007 to cap roaming charges. This will be of particular interest to Northern Irish users who inadvertently incur roaming charges when close to the Irish border. The first phase of this Europe-wide cap was introduced in 2007. In June 2010, the European Court of Justice struck down a challenge against this cap by Vodafone, O2 and other European mobile phone companies (who claimed that it was disproportionate). (Mintel 2010)

The Media Release by ODTR in March 8th 2001 showed that only a small proportion $(11 \%)$ of mobile users claim to have switched supplier in the past twelve months. The 
primary reasons for switching are special offers (24\%), change of phone $(22 \%)$ and better coverage/network (20\%). According to The Irish Times (May 2014), "Unhappy customers are finally making the switch. Irish consumers are no longer prepared to put up with poor customer service -72 per cent of us now active switchers, according to a new Accenture survey". Little wonder the consumer queries and complaints statistics published in September 2007 by ComReg clearly highlighted customers' frustrations on billing and installation \&

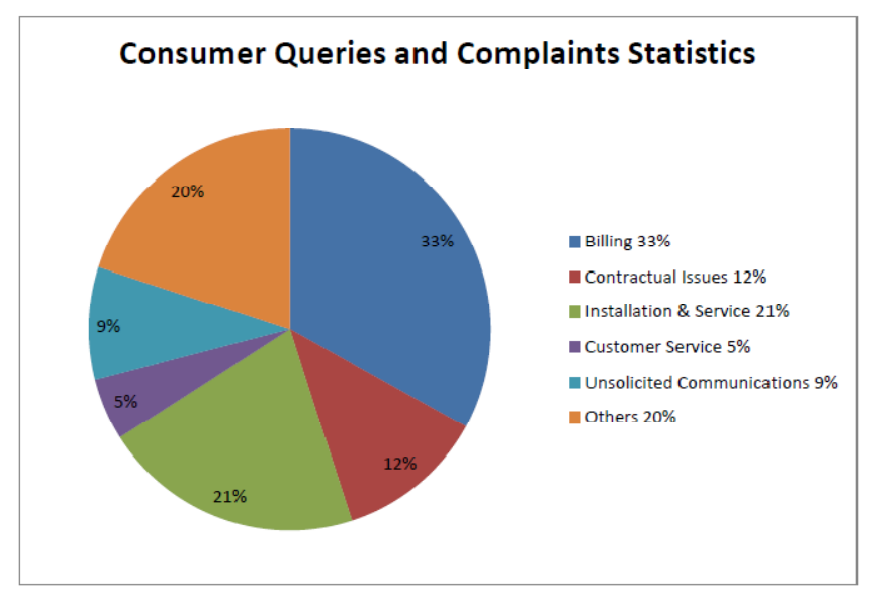

Figure 2.8: Consumer queries and complaints statistics

Source: ComReg, July to September 2007

In Ireland, the number of mobile phones surpasses the number of people. According to the national regulator, ComReg (2008), the Irish Republic has five million mobile subscriptions, despite the country's population standing at 4.2 million.

\section{Research Methods \& Methodology}

\section{Introduction to the research methodology}

This research will be undertaken from the view point of service quality in the mobile phone industry. It will emphasise among other things the relative importance of understanding the differences between humans in our role as social actors. We interpret our everyday social roles in accordance with the meaning we give to these roles and in addition, interpret the social roles of others in accordance with our own set of meanings (Saunders, M. et al., 2007). Social Actors such as customers may place many different interpretations on the situations in which they find themselves, so individual customers will perceive different situations in varying ways as a consequence of their own view of the world (Saunders, M.et al., 2007)

Business research does not exist in a vacuum. Not only it is shaped by what is going on in the real world of business and management; it is also shaped by many of the intellectual traditions that shape the social sciences at large (Bryman, A. and Bell, E. 2007). Research data are invariably collected in relation to something. The 'something' is often a pressing organisational problem, such as the effect of mergers and acquisitions on corporate culture or the impact of the introduction of new technology on employee motivation. Another scenario occurs when research is done on a topic when specific opportunity arises (Bryman, A. and Bell, E. 2007). In addition to the two stimuli for research mentioned above, Lofland and Lofland (1995) noted that many research publications emerge out of the researcher's personal biography. Research methodology according to Saunders, M., et al., (2007) is the theory of how research should be undertaken, including the theoretical and philosophical assumptions upon which research is based and the implications of these for the method or methods adopted. 


\section{Research design}

Research design according to Saunders et al., (2007) is the whole plan of how the researcher will go about answering his research question (s). This research involves different components of the research design to turn the researcher's question into a research project. Saunders stressed that this involves a research onion as a way of depicting these components. In this research some layers of this onion will be peeled away (i.e. outer layer) and the remaining layers would then focus on turning the researcher's question into answers by exploring customers' expectation of and perception of the service they receive from mobile phone providers. Figure 3.1 below illustrates Saunders et al., (2007) onion.

Source: Saunders et al., (2007)

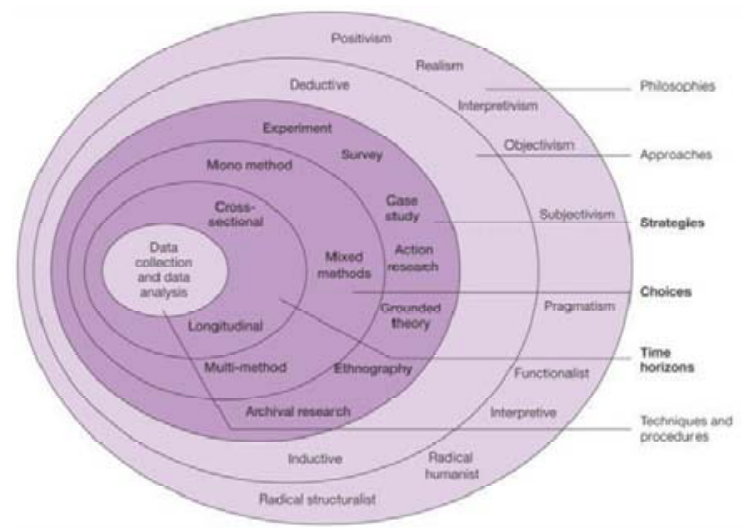

Figure 3.1: The research 'onion'

\section{Research problem area:}

in Ireland.

\section{Research Question:}

Why is there gap in service quality and what are those factors that affect customers' perceived service quality?

\section{Research Objectives:}

i. To explore the differences between expected and perceived service as experienced by users and to identify the service quality gaps using the modified SERVQUAL dimensions

ii. To critically examine the effect of customer satisfaction on loyalty and retention

iii. To examine the relationship between customer's cultural value orientations on their perceived service quality.

\section{Research philosophy}

The term research philosophy relates to the development of knowledge and the nature of that knowledge, and involves developing knowledge in a particular field (Saunders, M. et al., 2007). They argue that the research philosophy contains important assumptions about the way in which the researcher views the world and these assumptions will underpin the researcher's strategy. Since the researcher's philosophy relates to knowledge development, it is pertinent to note that the relationship between knowledge and the process by which it is developed is a very important aspect of the entire research cycle. Tashakkori and Teddlie, (1998) argued that a researcher should study what interests him and is of value to him, study in the different ways in which he deems appropriate, and use the results in ways that can bring about positive consequences within his value system.

According to Saunders, M. et al., (2007), the research philosophy can be viewed from three major perspectives: Epistemology, Ontology and Axiology. 
An epistemological issue concerns the question of what is (or should be) regarded as acceptable knowledge in a discipline (Bryman, A. and Bell, E. 2011). The core /central issue here is the question of whether or not the social world can and should be studied according to the same principles, procedures and ethos as the natural sciences. The position that affirms the importance of imitating the natural sciences is invariably associated with an epistemological position known as positivism.

Positivism according to Remenyi et al., (1998:32) applies when a researcher adopts the philosophical stance of the natural scientist. He pointed that the researcher using positivism works with an observable social reality and that the end product of such research can be lawlike generalisations.

The doctrine of positivism is extremely difficult to pin down and therefore to outline in a precise manner, because it is used in a number of ways by authors. For some writers, it is descriptive category-one that describes a philosophical position that can be discerned in research; and for others, it is a pejorative term used to describe crude and often superficial data collection (Bryman, A. and Bell, E. 2011)

Realism is another epistemological position which relates to scientific enquiry. The essence of realism is that what the senses show us as reality is the truth: that objects have an existence independent of the human mind. The theory of realism is that there is a reality quite independent of the mind. Based on this, realism is opposed to idealism, the theory that only the mind and its contents exist (Saunders, M. et al., 2007)

Interpretivism is an epistemology that advocates that it is necessary for the researcher to understand the differences between humans in our role as social actors. This emphasises the difference between conducting research among people rather than objects such as computers (Saunders, M. et al., 2007). Bryman, A. and Bell, E. (2011) equally argued that Interpretivism is taken to denote an alternative to the positivist orthodoxy that has held sway for decades. It is predicated upon the view that a strategy is required that respects the differences between people and the objects of the natural sciences and therefore requires the social scientists to grasp the subjective meaning of social action.

Ontology: The researcher highlighted previously that the key epistemological question is 'can the approach to the study of the social world, including that of management and business, be the same as the approach to studying the natural sciences'. Ontology on the other hand, is concerned with nature of reality. There are two aspects of ontology, and the first aspect is objectivism which portrays the position that social entities exit in reality external to social actors concerned with their existence. The second aspect, subjectivism, holds that social phenomena are created from the perceptions and consequent actions of those social actors concerned with their existence (Saunders, M. et al., 2007)

Axiology is a branch of philosophy that studies judgements about value, and the role that researcher's values play in all stages of the research process is of great importance in order for the research results to be credible (Saunders, M. et al., 2007). Heron (1996) argues that our values are the guiding reason of all human action. The researcher's choice of philosophical approach is a reflection of his values, as is his choice of data collection techniques.

In this research project, the researcher applied the philosophy of positivism. Though the researcher will prefer working with an observable social realities and equally tries to understand the differences between humans in our role as social actors he will vehemently avoid generalisations. This is because data collected will be analysed \& interpreted statistically in order to test the hypotheses.

\section{Research approach}

Research approach is a general term for deductive and inductive research method. Deductive approach is an approach in which the researcher develops a theory and hypothesis (or hypotheses) and designs a research strategy to test the hypothesis. On the other hand, Inductive approach is an approach in which the researcher would collect data and develop 
theory as a result of his data analysis (Saunders, M. et al., 2007). Deductive theory represents the most common view of the nature of the relationship between theory and research. The researcher on the basis of what is known about a particular domain and of theoretical

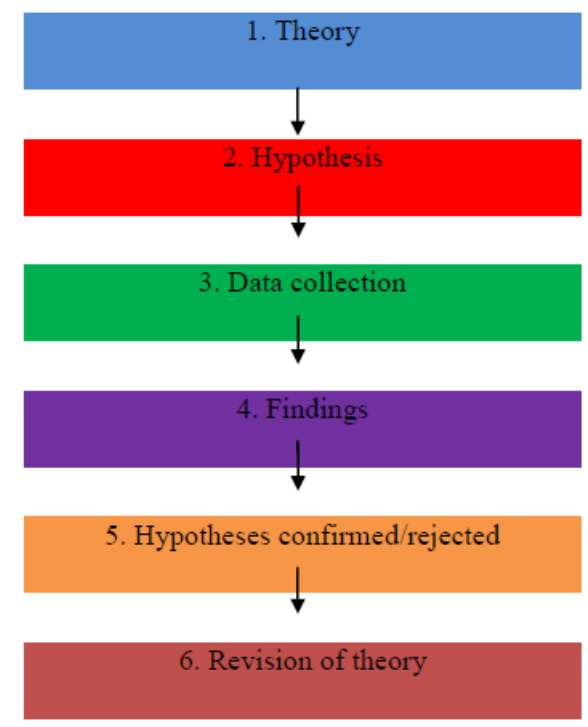

Figure 3.2: The sequence/process of deduction

Source: Business Research Methods, by Bryman and Bell (2011)

Research using an inductive approach, according to Saunders et al., (2007) is likely to be particularly concerned with the context in which such events were taking place. They argued that if a researcher is particularly interested in understanding why something is happening, rather than being able to describe what is happening, it may be more appropriate to undertake the research inductively rather than deductively. Followers of induction would criticise deduction because of its tendency to construct a rigid methodology that does not permit alternative explanations of what is going on. In that sense, they stressed, there is an air of finality about the choice of theory and definition of the hypothesis.

The deductive approach will be used in this research by the researcher because of the symbiotic relationship with positivism which is a subset of an epistemological position that supports the methods of the natural sciences to the study of social reality and beyond. The use of this approach by the researcher will highlight in no small measure the need to explain causal relationships between variables (in this context-SERVQUAL dimensions) This approach will equally showcase researcher's independence of what is being researched.

Based on the above and also on the review of literature, the researcher's:

Theoretical Proposition is: Customer satisfaction has a significant influence on customers' perceived service quality

\section{Specific Hypotheses are:}

1. Customer satisfaction has a significant influence on loyalty

2. The higher the perceived network quality, the greater the level of loyalty from customers

3. Price has a significant influence on customers' perception of service from mobile providers in Ireland.

In addition to the above reasons for the choice of deductive approach, this method is advantageous because there is wealth of literature from which the researcher can define a theoretical framework and a hypothesis. Deductive research can also be quicker to complete and it's normally possible to predict the time schedules accurately (Saunders et al., 2007) Another point to bear in mind is that the deductive process appears very linear-one step follows the other in a clear, logical sequence ((Bryman, A. and Bell, E. 2011). In order to test 
the above hypotheses with a view to closing the service quality gaps, the researcher will totally move away from "test room method" and will adopt a more quantitative strategy. Survey questionnaires will be used to gather data from respondents. This strategy will be undertaken to establish the effect of variables which are broken down from the hypotheses.

\section{Research strategy}

Research Strategy according to Saunders et al., (2007) is the general plan of how the researcher will go about answering the research question (s) and at the same time meets the research objectives. This was echoed by (Bryman, A. and Bell, E. (2011) who defined research strategy as a general orientation to the conduct of business research. Saunders et al., (2007) identified seven types of research strategies, namely:

3.5.1 Experiment which tends to be used in exploration and explanatory research to answer 'how' and 'why' questions is a classical form of research that focuses on natural sciences, though it can be used in social science research. The purpose of an experiment is to study causal links; whether a change in one independent variable produces a change in another dependent variable (Hakim, 2000). An experiment involves typically: definition of a theoretical hypothesis; selection of samples of individuals from known populations; random allocation of samples to different experimental conditions, the experimental group and the control group; introduction of planned intervention or manipulation to one or more of the variables, and control of all other variables (Saunders et al., A. 2007).

3.5.2 A Survey strategy is a popular and common strategy in business and management research and is most frequently used to answer who, what, where, how much and how many questions. It is usually associated with the deductive approach and tends to be used for exploratory and descriptive research. Surveys are popular as they allow the collection of a large amount of data from a sizeable population in a highly economical way. These data are often obtained by using a questionnaire administered to a sample and are standardised, allowing easy comparison. These quantitative data which this survey strategy allows the researcher to collect could be analysed quantitatively using descriptive and inferential statistics (Saunders et al., 2007). They further argued that these data collected via the survey strategy could be used to suggest possible reasons for particular relationships between variables and to produce models of these relationships.

3.5.3 Case Study is a research strategy that entails the detailed and intensive analysis of a single case and can be associated with both theory generation (i.e. from the findings) and theory testing (Saunders et al., 2007). Robson (2002: 178) defines case study as a strategy for doing research which involves an empirical investigation of a particular contemporary phenomenon within its real life context using multiple sources of evidence. The case study strategy will be of particular interest to a researcher if he wishes to gain a rich understanding of the context of the research and the processes being enacted (Morris and Wood, 1991).

3.5.4 Action Research. Bryman, A. and Bell, E. (2011) defined action research as a strategy in which the action researcher and a client collaborate in the diagnosis of a problem and in the development of a solution based on the diagnosis. Action research differs from other research strategies because of its explicit focus on action, in particular promoting change within the organisation. It is particularly useful for 'how' questions and in addition, the person undertaking the research is involved in this action for change and subsequently application of the knowledge gained elsewhere.

3.5.5. Grounded Theory. This strategy is according to Goulding (2002), particularly helpful for research to predict and explain behaviour, the emphasis being upon developing and building theory. In grounded theory, Saunders et al., (2007), argued that data collection starts without the formation of an initial theoretical framework. Theory is developed from data generated by a series of observations.

3.5.6. Ethnography originates from the field of anthropology and the purpose is to describe and explain the social world the research subjects inhabit in the way in which they would describe and explain it. It is in no doubt a research strategy that is very time consuming 
and takes place over an extended time period as the researcher needs to immerse him/herself in the social world being researched as completely as possible (Saunders et al., 2007).

3.5.7. Archival Research strategy enables the researcher to make use of administrative records and documents as the principal source of data. Although the term archival has historic connotations, it can refer to recent as well as historical documents (Bryman, 1989). It is pertinent to note that all research that makes use of data contained in administrative records is inevitably secondary data analysis because the data were originally collected for a different purpose, the administration of the organisation (Saunders et al., 2007).

The researcher believes that since this research project will be adopting the deductive approach, a survey strategy will be used. The main aim of the research is to explore customers' expectation and perception of the service they receive from mobile phone providers. This obviously aims to seek new insights into service quality gap which undoubtedly will require asking the Who, what, how much and how many questions from mobile phone subscribers, hence the choice of survey strategy. As it will be very cumbersome to collect data from the entire country (Ireland), questionnaires will be administered to a specific population within Ireland which the researcher deems representative of the whole country, and at a lower cost. Be that as it may, there are few concerns about using this approach which include: more time is spent in ensuring that the chosen population is representative; analysing the results, even with readily available analysis software will also be time consuming (Saunders et al., 2007).

\section{Population \& sample}

A population is the universe of units from which a sample is to be selected (Bryman, A. and Bell, E. 2011). For the purpose of this research, the definition of population is: All Households in Esker Woods, Lucan, County Dublin Ireland.

The above population is made of various components:

- Elements- Households in Esker Woods

- Units- Esker Woods

- Extent- Esker Woods, Lucan, County Dublin

- Time- Autumn 2015

The combined factors of time and budgetary constraints have made it practically impossible to collect data from the entire population of Ireland hence the definition of specific population above. The researcher believes that the definition of Esker Woods as a chosen population in this research is representative. This chosen population will be a sub-set of the population of Ireland. The researcher will collect and analyse data from all households in the chosen population, therefore employing census method, and the data are treated as census data. Census, according to Bryman, A. and Bell, E. (2011) is the enumeration of an entire population.

There are six units in the chosen population (Esker Woods) which contain 128 potential respondents. The figure below shows the six units:

$\begin{array}{lccc} & \begin{array}{c}\text { NUMBER OF SEMI- } \\ \text { DETACHED } \\ \text { HOUSES }\end{array} & \begin{array}{c}\text { NUMBER OF } \\ \text { HOUSEHOLDS IN } \\ \text { ONE SEMI- } \\ \text { DETACHED HOUSE }\end{array} & \begin{array}{c}\text { TOTAL NUMBER } \\ \text { OF HOUSEHOLDS } \\ \text { IN ESKERWOODS }\end{array} \\ \begin{array}{l}\text { ESKER WOODS } \\ \text { DRIVE }\end{array} & 15 & 2 & 15 \times 2=30 \\ \begin{array}{l}\text { ESKER WOODS } \\ \text { CLOSE }\end{array} & 12 & 2 & 12 \times 2=24 \\ \begin{array}{l}\text { ESKER WOODS } \\ \text { WALK }\end{array} & 4 & 2 & 4 \times 2=8 \\ \begin{array}{l}\text { ESKER WOODS } \\ \text { GROVE }\end{array} & 4 & 2 & 4 \times 2=8 \\ \text { ESKER WOODS } & 14 & 2 & 14 \times 2=28 \\ \text { COURT } & & & \end{array}$


South American Journal of Management

Special Edition 2016

ESKER WOODS

VIEW

TOTAL
15

2

64
$15 \times 2=30$

128

Figure 3.3: Sampling frame for population

\section{Time horizons}

Time is a very important variable when carrying out a research. The researcher believes that there is a natural phenomenon that whatever has a beginning must have an end but it's a matter of time. Research project is no exception. When planning a research, Saunders et al., (2007) highlighted that the very momentous question the researcher will ask is whether the research will be a snapshot taken at a particular time or does the researcher want it to be more akin to a diary and be a representation of events over a given period. The 'snapshot' time horizon is called cross-sectional while the 'diary' perspective is called longitudinal. Due to the fact that this research will be time constrained, data will be gathered just once, perhaps over a period of days or weeks or months, in order to answer the research question. Such studies are called one-shot or cross-sectional research (Sekaran, U. 2003). The choice of this cross-sectional research was made because this research focuses on a particular phenomenon (i.e. the exploration of customer's expectation of and perception of the services they receive from mobile providers, which is a situation that is observed to exist or happen) at a particular time.

\section{Ethical issues}

In this research process, there are bound to be some ethical issues which will need to be addressed. The researcher thinks that unaddressed ethical issues might not only derail the entire research process but might envelope into a bowl of flame that will be difficult to extinguish. Saunders, M. et al., (2007) points out that research ethics has important implications for the negotiation of access to people and organisations and the collection of data and also defined personal data as any information relating to identified or identifiable persons.

In the course of this research, there will be data protection concerns and the researcher acting within the confines of the law will apply openness throughout the research process. By openness, the researcher means that all questions on the questionnaire will be copiously explained to the respondent, and sensitive questions should be avoided. Before conducting the survey the researcher will educate the participants on their ethical and legal rights. The researcher will also seek respondent's consent especially before distributing the questionnaires making sure that ethical issues of confidentiality and anonymity will be addressed. He equally thinks that all potential issues that might degenerate or pose ethical dilemma should be addressed.

Every effort will be made to work within the confines of the data protection act of the land. Little wonder the mission statement of Office of The Data Protection Commissioner of Ireland is, "To protect the individual's right to privacy by enabling people to know, and to exercise control over how their personal information is used, in accordance with the Data Protection Acts, 1988 and 2001". http://dataprotection.ie/docs/Home/4.htm. This office also defined data protection as your fundamental right to privacy. The ethical issues of confidentiality will be applied in the whole stages of this research i.e. data collection; data processing and storage; data analysis and reporting.

\section{Data collection techniques}

Most business and management researchers in trying to answer their research question (s) or meet their objectives consider initially the possibility of reanalysing data that have already been collected for some other purpose. Such data are known as secondary data. On the other hand, many other researchers think in terms of collecting new (primary) data specifically for that purpose (Saunders et al., 2007). They highlighted that secondary data include both raw 
data and published summaries because most organisations collect and store a variety of data to support their operations: for example, payroll details, copies of letters, minutes of meetings and accounts of sales of goods or services. Primary sources include: Observation; Interviewing and Questionnaires.

There are two types of primary data collection which are quantitative and qualitative data. One way of differentiating between the two, according to Saunders et al., (2007) is the focus on numeric (numbers) or non-numeric (words) data. They pointed out that quantitative data is predominantly used as a synonym for any data collection technique (such as questionnaire) or data analysis procedure (such as graphs or statistics) that generates or uses numerical data. In contrast, qualitative data is used predominantly as a synonym for any data collection technique (such as an interview) or data analysis procedure (such as categorising data) that generates or uses non-numerical data. Bryman, A. and Bell, E. (2011) summed it up and pointed out that quantitative research can be construed as a research strategy that emphasises quantification in the collection and analysis of data. In contrast, qualitative research can be construed as a research strategy that usually emphasises words rather than quantification in the collection and analysis of data (See figure 3.4)

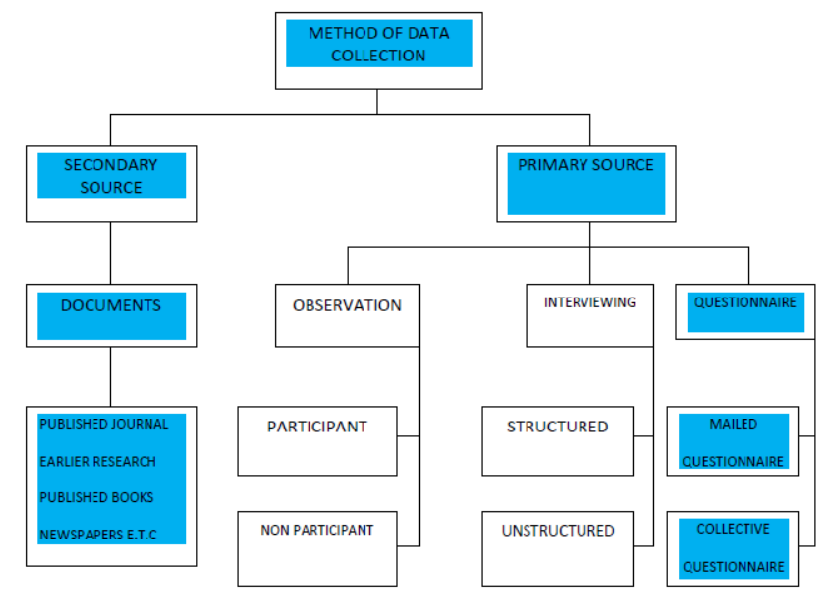

Figure 3.4: Methods of data collection

For the purpose of this research the researcher applied both primary and secondary sources for collecting data. This combination is essential in order to answer the research question and meet the objectives. The data collection from secondary sources would be mainly from academic journals, publications and textbooks, newspapers.

\section{Qualitative Data Collection}

Under the primary sources of data collection, the researcher had employed a quantitative method (specifically questionnaires) approach therefore qualitative method will not be used.

\section{Quantitative Data Collection}

The researcher has employed the quantitative research method (under primary sources), the Survey to collect data for this research. A survey is a research strategy that involves the structured collection of data from a sizeable population and the term 'survey' is often used to describe the collection of data using questionnaires (Saunders et al., 2007) The researcher in the bid to answer the research question and meet the objectives has modified the original SERVQUAL instruments (as mentioned above) to suit the telecommunication industry. The questionnaire was therefore designed considering this modification and answering the research question. Questionnaire is a general term which includes all techniques of data collection in which each person is asked to respond to the same set of questions in a predetermined order. It includes structured interviews and telephone questionnaires as well as 
those in which the questions are answered without an interviewer being present, such as online questionnaire (de Vaus, 2002).

Saunders et al., (2007) pointed that the design of questionnaire differs according to how it is administered and in particular, the amount of contact the researcher has with the respondents. They further highlighted that self-administered questionnaires are usually completed by the respondents. Such questionnaires are administered electronically using the internet (internet-mediated questionnaires) or intranet (intranet-mediated questionnaires), posted to respondents who return them by post after completion (postal or mail questionnaires), or delivered by hand to each respondent and collected later (delivery and collection questionnaires). Interviewer-administered questionnaires on the other hand could be used in the form of telephone questionnaire and structured interview. The researcher employed delivery and collection questionnaire method because of the friendly and longstanding relationship with most of the respondents. Questionnaires were therefore delivered by hand to each respondent and collected later and according to Saunders et al., (2007), with delivery and collection questionnaires, the researcher can sometimes check who has answered the questions at collection.

\section{Questionnaire Design}

The choice of questionnaire will be influenced by a variety of factors related to the research question (s) and objectives and in particular the: characteristics of the respondents from whom the researcher wishes to collect data; importance of reaching a particular person as respondent; importance of respondents' answers not being contaminated or distorted; size of sample the researcher requires for his analysis, taking into account the likely response rate; types of questions the researcher needs to ask to collect his data; number of questions the researcher needs to ask to collect his data (Saunders et al., 2007). The researcher has not only defined the theories he wishes to test as relationships between variables, but has also reviewed the literature carefully prior to designing his questionnaire. Foddy (1994:17) emphasises that 'the question must be understood by the respondent in the way intended by the researcher and the answer given by the respondent must be understood by the researcher in the way intended by the respondent'

Figure 3.5 below shows the stages that must occur if a question is to be valid and reliable

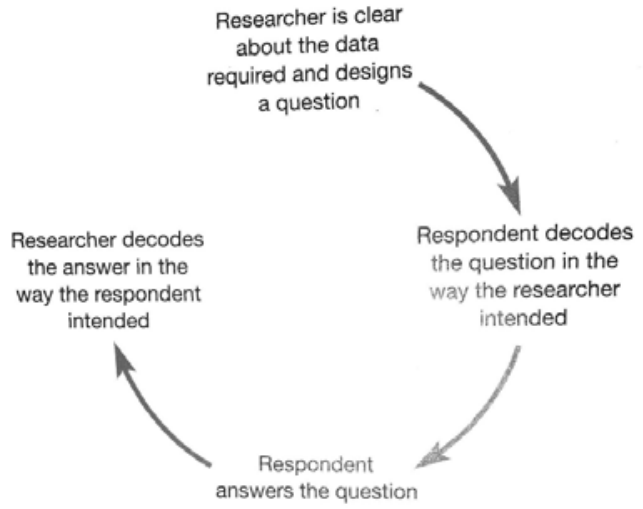

Figure 3.5: Stages that must occur if a question is to be valid and reliable

Source: Foddy, W. (1994)

The questionnaire was designed primarily to: (See research objectives in 3.2.3)

\section{Questionnaire Content, layout and Wording}

The contents of the questionnaire are well structured with responses properly formatted. The respondents were given the option to choose from multiple-choice answers to ratings scales (using likert scales). The questions were designed in a manner that reading questions and filling in responses was easy. The layout of questionnaire was very attractive and 
appealing and this would encourage the respondents to fill and return them. The questions are not too long and are not cramped. However, where the choice is between an extra page and a cramped questionnaire the former is likely to be more acceptable to respondents (Dillman, 2000).

\section{Pre-Testing/Modifications in the Questionnaire}

A pilot survey or pre-test is simply a trial run on the main survey undertaken to test the questionnaire, the reaction of respondents, and the researcher's procedures for carrying out the survey (Brannick, T. and Roche, W.K. 1997). The purpose of the pilot test according to Saunders et al., (2007) is to refine the questionnaire so that respondents will have no problems in answering the questions and there will be no problems in recording the data. In order to identify errors and also technical and ambiguous questions which might affect the respondents when answering the questions, the researcher distributed a number of drafts to be completed by potential respondents. The draft questionnaire was distributed to a number of work colleagues and also college mates (totalling 23) to be pre-tested. The feedback was immeasurable because there were a number of issues which needed to be corrected. The pretest uncovered that some questions are too long, unclear and ambiguous. Most of these colleagues commented that the layout wasn't attractive. These mistakes were corrected in conjunction with the application of spell-check to ensure that there are no grammatical errors and the final draft was produced.

The pilot survey discussed above was carried out primarily to determine the suitability, readability and ambiguity of the SERVQUAL instruments and to extract additional service quality criteria if need be using open-ended questions. Though the majority of the participants in the pilot survey felt that the five dimensions of SERVQUAL model (tangibles, reliability, responsiveness, assurance and empathy) were appropriate for use in the Irish mobile telecommunications few participants felt that there are gaps which need to be filled. They found that there are still some dimensions that need to be introduced. According to the participants, network aspect, service convenience, loyalty and pricing should be added to the original five dimensions in order to provide answers as to why there is service quality gap. Accordingly, the new dimensions were incorporated in the questionnaire used in the final survey.

The final instrument therefore used 33 statements with nine dimensions (see appendix 10) of tangibles, reliability, responsiveness, assurance, empathy, network aspect, convenience, loyalty and pricing. Of these 33 items, 21 items were taken from the original SERVQUAL instruments and modified to telecommunications industry. One item (of the 21 items) related to "service provider provides services at the promised time" was deleted from the reliability dimension as it was found to convey same message with the item "when service provider promises to do something by a certain time, it will do" by the participants of the pilot survey. Another item "the appearance of the physical facilities will be in line with the type of services provided" from tangibles dimension was equally removed because participants saw no need for that and argued that it has no relevance to bridging the service quality gap. One more item "service provider will have operating hours convenient to all its customers" from empathy dimension was also removed and transferred to another dimension, "Convenience" as participants highlighted that it would be proper to be with that rather than with "empathy". The remaining 18 items from the original SERVQUAL dimensions were then added to the 15 new items to make a total of 33 items.

The researcher clarifies that cultural issue which was reflected in the literature review was not included in the questionnaire as participants in the pilot survey felt that it has a broad spectrum and argued that culture is a sensitive issue and that the questionnaire will not give the respondents enough opportunities to answer the cultural questions in detail. For the measurement of the service customers receive from mobile phone providers in Ireland, the researcher has employed the nine modified SERVQUAL dimensions using a five- point Likert scale. This scale includes 'strongly agree', 'agree', 'undecided', 'disagree', and 
'strongly disagree'. 31 out of 33 items were measured using the five-point Likert scale, and the remaining two, "service provider will have up-to-date equipment" under tangibles dimension, Yes or No answer was used. In the other item, "service provider will be dependable", a three-point Likert scale was used as the researcher found it more appropriate and straight to the point. Among the tools of measuring service quality that focus external perspective, SERVQUAL developed by Parasuraman et al. (1988), seems to be useful and widely adopted by researchers (Hoffman and Bateson, 2001).

\section{Data Analysis and Findings}

This chapter covers the analysis of data collected via survey method-questionnaires. The essence of this chapter from the researcher's perspective is not only to highlight the research question/objectives but also to proffer answer(s) to the question. The researcher will also try and put the data collected via the questionnaires in juxtaposition with the theories derived from related research literature and subsequently test the research hypotheses.

\section{Quantitative data editing and coding}

\section{Demographics of the respondents}

\section{Q1. Gender distribution}

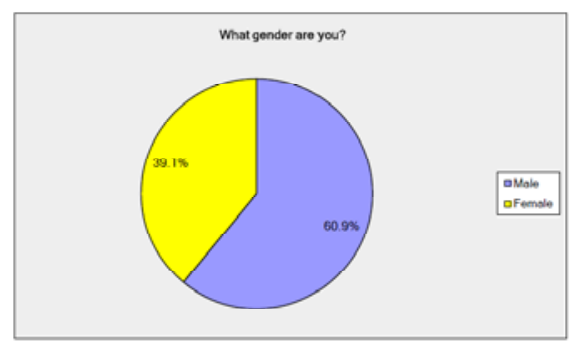

Figure 4.1: Charts for gender distribution

\begin{tabular}{|l|c|c|}
\hline \multicolumn{3}{|l|}{ What gender are you? } \\
\hline Answer Options & Response Percent & Response Count \\
\hline Male & $60.9 \%$ & 70 \\
\hline Female & $39.1 \%$ & 45 \\
\hline & answered question & 115 \\
\hline & skipped question & 0 \\
\hline
\end{tabular}

Figure 4.2: Table for gender distribution

\section{Q2. Age groups}

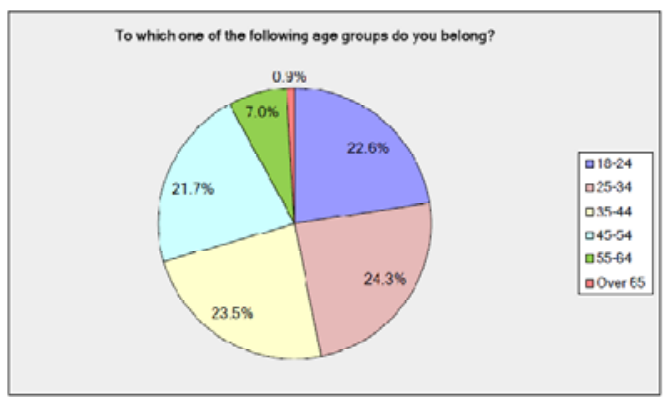

Figure 4.3: Chart for age distribution

\begin{tabular}{|l|c|c|}
\hline $\begin{array}{l}\text { To which one of the } \\
\text { following age groups do } \\
\text { you belong }\end{array}$ & Response Percent & Response Count \\
\hline $18-24$ & $22.6 \%$ & 26 \\
\hline
\end{tabular}


Volume 3, Issue 1, 2016

\begin{tabular}{|l|c|c|}
\hline $25-34$ & $24.3 \%$ & 28 \\
\hline $35-44$ & $23.5 \%$ & 27 \\
\hline $45-54$ & $21.7 \%$ & 25 \\
\hline $55-64$ & $7.0 \%$ & 8 \\
\hline Over 65 & $0.9 \%$ & 1 \\
\hline & answered question & 115 \\
\hline & skipped question & 0 \\
\hline
\end{tabular}

Figure 4.4: Table for age distribution

\section{Q3. Level of Education}

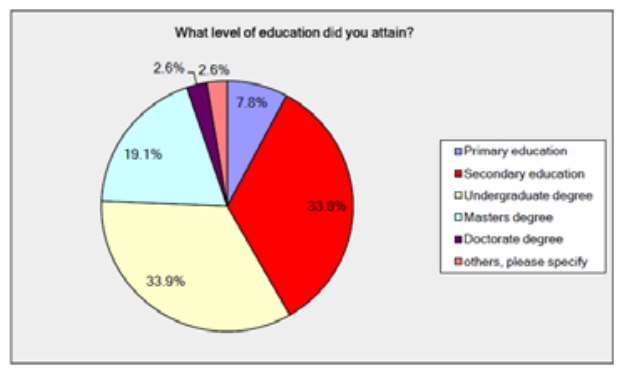

Figure 4.5: Chart for level of education

\begin{tabular}{|l|c|c|}
\hline $\begin{array}{l}\text { What level of education } \\
\text { did you attain? }\end{array}$ & Response Percent & Response Count \\
\hline Primary education & $7.8 \%$ & 9 \\
\hline Secondary education & $33.9 \%$ & 39 \\
\hline Undergraduate degree & $33.9 \%$ & 39 \\
\hline Masters degree & $19.1 \%$ & 22 \\
\hline Doctorate degree & $2.6 \%$ & 3 \\
\hline others, please specify & $2.6 \%$ & 3 \\
\hline & answered question & 115 \\
\hline & skipped question & 0 \\
\hline
\end{tabular}

Figure 4.6: Table for level of education

\section{Q4. Network Provider}

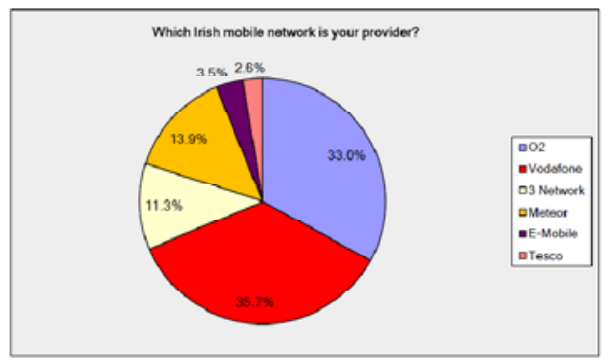

Figure 4.7: Chart for network provider distribution

\begin{tabular}{|l|c|c|}
\hline $\begin{array}{l}\text { Which Irish } \\
\text { mobile network } \\
\text { is your } \\
\text { provider? }\end{array}$ & Response Percent & Response Count \\
\hline O2 & $33.0 \%$ & 38 \\
\hline Vodafone & $35.7 \%$ & 41 \\
\hline 3 Network & $11.3 \%$ & 13 \\
\hline Meteor & $13.9 \%$ & 16 \\
\hline
\end{tabular}


South American Journal of Management Special Edition 2016

\begin{tabular}{|l|c|c|}
\hline E-Mobile & $3.5 \%$ & 4 \\
\hline Tesco & $2.6 \%$ & 3 \\
\hline & answered question & 115 \\
\hline & skipped question & 0 \\
\hline
\end{tabular}

Figure 4.8: Table for network provider distribution

\section{Q5. Method of Payment}

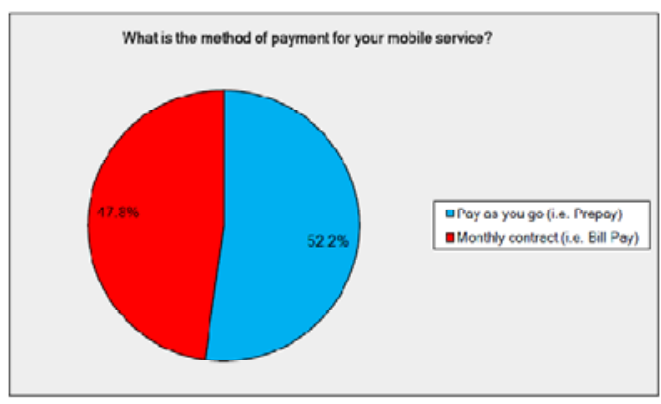

Figure 4.9: Chart for method of payment

\begin{tabular}{|l|c|c|}
\hline $\begin{array}{l}\text { What is the method of payment for } \\
\text { your mobile service? }\end{array}$ & Response Percent & Response Count \\
\hline Pay as you go (i.e. Prepay) & $52.2 \%$ & 60 \\
\hline Monthly contract (i.e. Bill Pay) & $47.8 \%$ & 55 \\
\hline & answered question & 115 \\
\hline & skipped question & 0 \\
\hline
\end{tabular}

Figure 4.10: Table for method of payment

\section{Service quality dimensions}

\section{Q6. Tangibles (A)}

There are three items in this dimension type hence the numbering, tangibles (A, B, C). These three items will measure customers' satisfaction individually.

\begin{tabular}{|l|c|c|}
\hline \multicolumn{3}{|c|}{ Do you think your service provider has up-to-date equipment? } \\
\hline Answer Options & Response Percent & Response Count \\
\hline Yes & $82.6 \%$ & 95 \\
\hline No & $15.7 \%$ & 18 \\
\hline Others & $1.7 \%$ & 2 \\
\hline & answered question & 115 \\
\hline & skipped question & 0 \\
\hline
\end{tabular}

Figure 4.11: Table for provider having up to date equipment

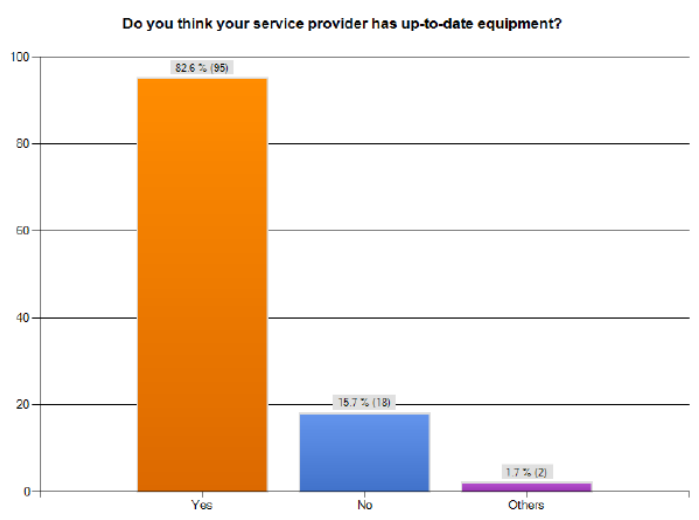


Figure 4.12: Chart for provider having up to date equipment

The figure 4.11 above showed that a total of 115 responded to that question and 95 of these concurred that their service providers have up-to-date equipment while 18 answered 'no'. The remaining 2 respondents neither answered 'yes' nor 'no'

\section{Q7. Tangibles (B)}

The physical facilities at my service provider are visually appealing

\begin{tabular}{|l|c|c|}
\hline Answer Options & Response Percent & Response Count \\
\hline Strongly agree & $21.7 \%$ & 25 \\
\hline Agree & $47.8 \%$ & 55 \\
\hline Undecided & $23.5 \%$ & 27 \\
\hline Disagree & $7.0 \%$ & 8 \\
\hline Strongly Disagree & $0.0 \%$ & 0 \\
\hline & answered question & 115 \\
\hline & skipped question & 0 \\
\hline
\end{tabular}

Figure 4.13: Table for physical facilities being visually appealing

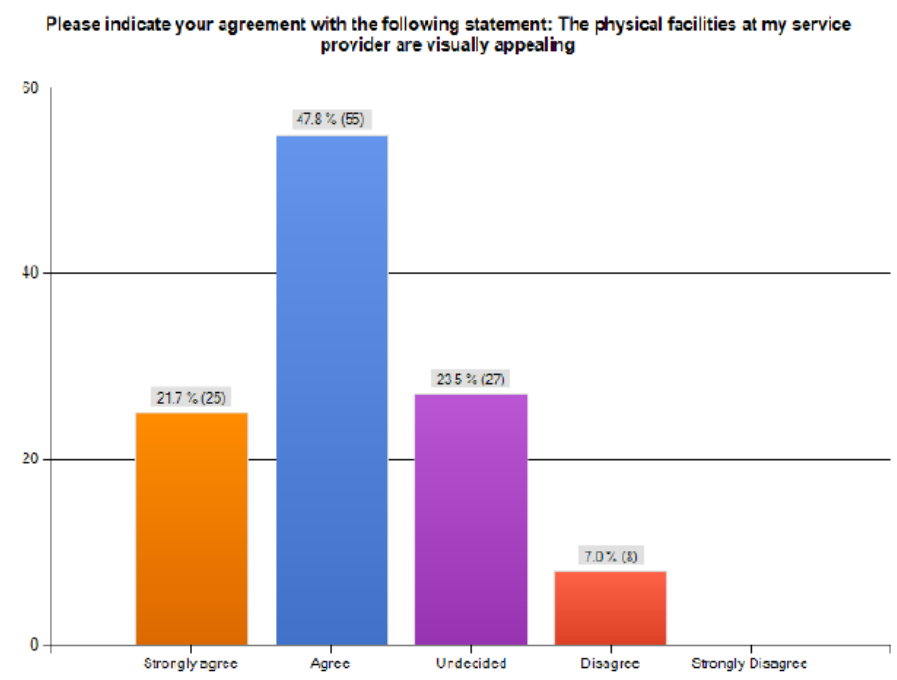

Figure 4.14: Chart for physical facilities being visually appealing

It was revealed from figure 4.13 above that $47.8 \%$ of 115 respondents agreed that the physical facilities at their service provider are visually appealing and only $7.0 \%$ disagreed with the statement.

\section{Q8. Tangibles (C)}

\begin{tabular}{|l|c|c|}
\hline \multicolumn{3}{|c|}{ The employees at my service provider appear neat and well dressed } \\
\hline Answer Options & Response Percent & Response Count \\
\hline Strongly agree & $14.8 \%$ & 17 \\
\hline Agree & $55.7 \%$ & 64 \\
\hline Undecided & $21.7 \%$ & 25 \\
\hline Disagree & $7.8 \%$ & 9 \\
\hline Strongly disagree & $0.0 \%$ & 0 \\
\hline & answered question & 115 \\
\hline & skipped question & 0 \\
\hline
\end{tabular}

Figure 4.15: Table for providers employees appearing neat/well dressed 
South American Journal of Management

Special Edition 2016

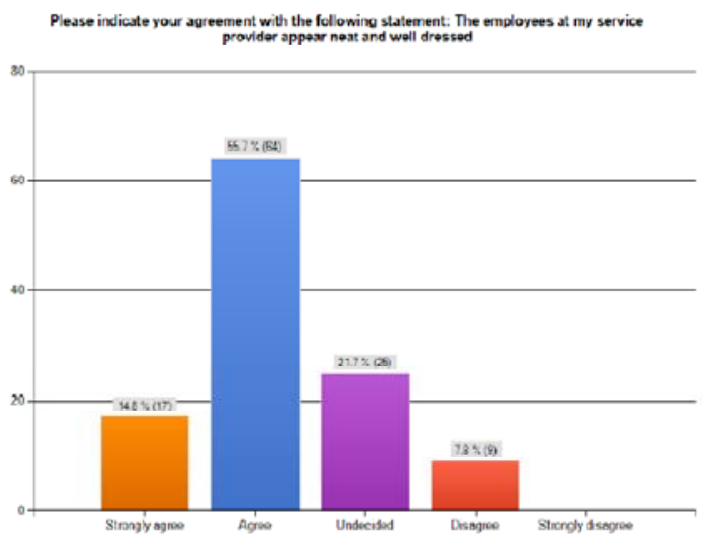

Figure 4.16: Chart for providers' employees appearing neat/well-dressed

Figure 4.15 above shows that $55.7 \%$ of the 115 respondents agreed that the employees at their service providers appear neat and well dressed while $7.8 \%$ disagreed with the statement

\section{Q9. Reliability (A)}

\begin{tabular}{|l|c|c|}
\hline My service provider delivers on its promises \\
\hline Answer Options & Response Percent & Response Count \\
\hline Strongly agree & $16.5 \%$ & 19 \\
\hline Agree & $48.7 \%$ & 56 \\
\hline Undecided & $23.5 \%$ & 27 \\
\hline Disagree & $10.4 \%$ & 12 \\
\hline Strongly disagree & $0.9 \%$ & 1 \\
\hline & answered question & 115 \\
\hline & skipped question & 0 \\
\hline
\end{tabular}

Figure 4.17: Table for provider delivering services as promised

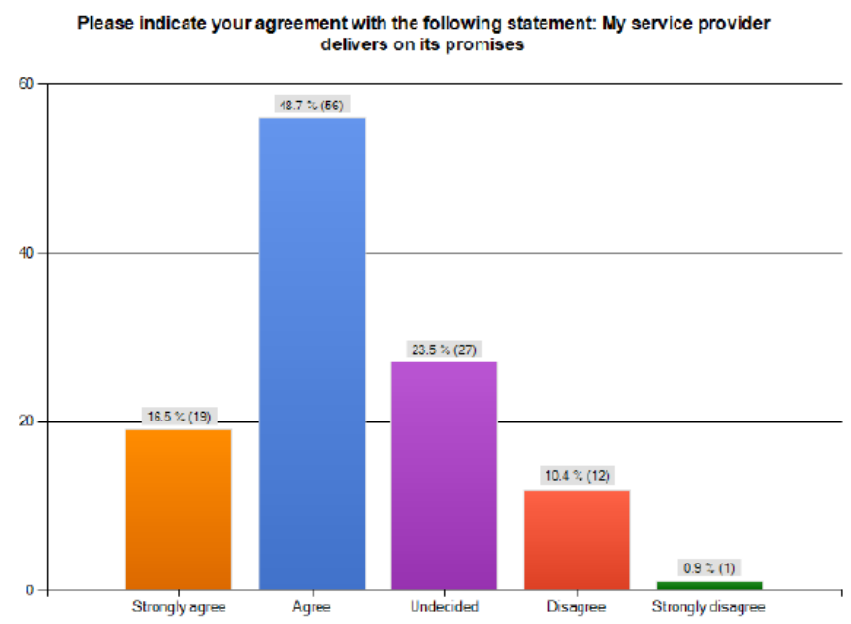

Figure 4.18: Chart for provider delivering services as promised

$48.7 \%$ of respondents from figure 4.17 above are satisfied that their service providers deliver on their promises and $10.4 \%$ disagreed to that.

Q10. Reliability (B)

My service provider shows a sincere interest in solving my problem

\begin{tabular}{|l|l|l|}
\hline Answer Options & Response Percent & Response Count \\
\hline
\end{tabular}


Volume 3, Issue 1, 2016

\begin{tabular}{|l|c|c|}
\hline Strongly agree & $14.8 \%$ & 17 \\
\hline Agree & $47.0 \%$ & 54 \\
\hline Undecided & $22.6 \%$ & 26 \\
\hline Disagree & $13.9 \%$ & 16 \\
\hline Strongly disagree & $1.7 \%$ & 2 \\
\hline & answered question & 115 \\
\hline & skipped question & 0 \\
\hline
\end{tabular}

Figure 4.19: Table for service provider showing sincere interest in solving customer's problems

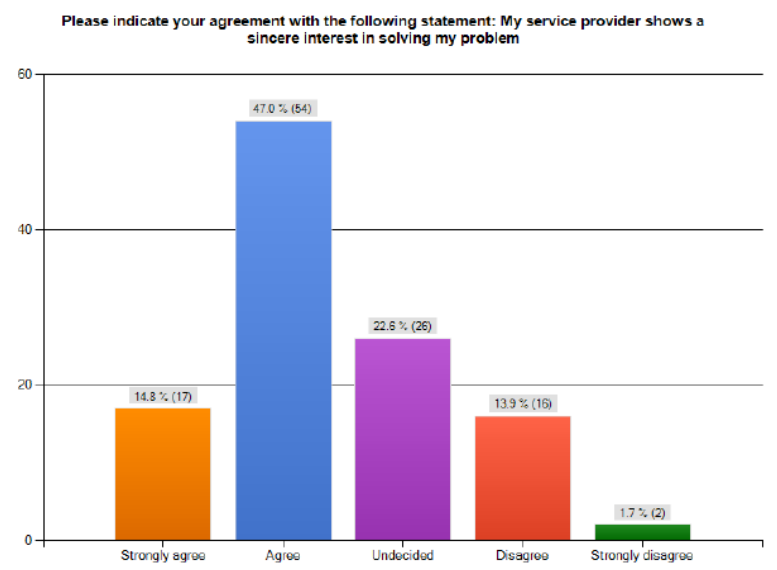

Figure 4.20: Chart for service providers showing sincere interest in solving customer's problems

Figure 4.19 shows that $47.0 \%$ of the 115 respondents agreed that their service provider shows a sincere interest in solving their problems. $13.9 \%$ of the respondents disagreed with the statement.

\section{Q11. Reliability (C)}

\begin{tabular}{|l|c|c|}
\hline \multicolumn{3}{|l|}{ I trust my service provider } \\
\hline Answer Options & Response Percent & Response Count \\
\hline Completely trust provider & $53.0 \%$ & 61 \\
\hline Undecided & $29.6 \%$ & 34 \\
\hline Do not trust provider & $17.4 \%$ & 20 \\
\hline & answered question & 115 \\
\hline & skipped question & 0 \\
\hline
\end{tabular}

Figure 4.21: Table showing customer's trust on the service provider

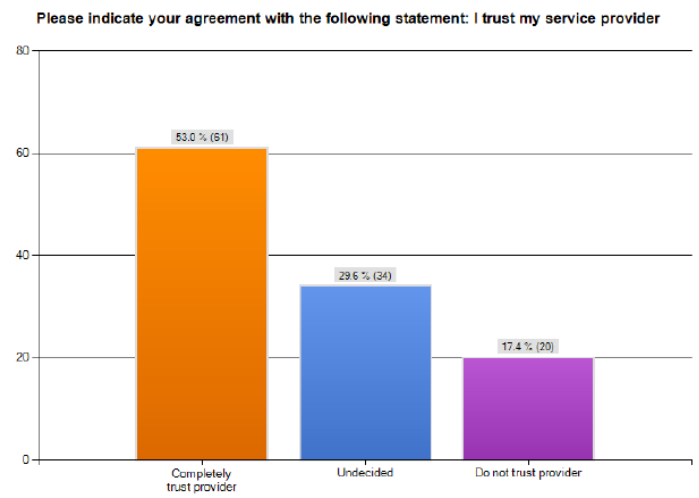

Figure 4.22: Chart showing customer's trust on the service provider 
South American Journal of Management

Special Edition 2016

From table 4.21 above, $53.0 \%$ out of 115 respondents completely trust their service provider while $17.4 \%$ did not trust their provider.

Q12. Reliability (D)

\begin{tabular}{|l|l|l|}
\hline \multicolumn{3}{|l|}{ My service provider keeps accurate records } \\
\hline Answer Options & Response Percent & Response Count \\
\hline Strongly agree & $16.5 \%$ & 19 \\
\hline Agree & $55.7 \%$ & 64 \\
\hline Undecided & $19.1 \%$ & 22 \\
\hline Disagree & $7.8 \%$ & 9 \\
\hline Strongly disagree & $0.9 \%$ & 1 \\
\hline & answered question & 115 \\
\hline & skipped question & 0 \\
\hline
\end{tabular}

Figure 4.23: Table showing whether service provider keeps accurate record or not

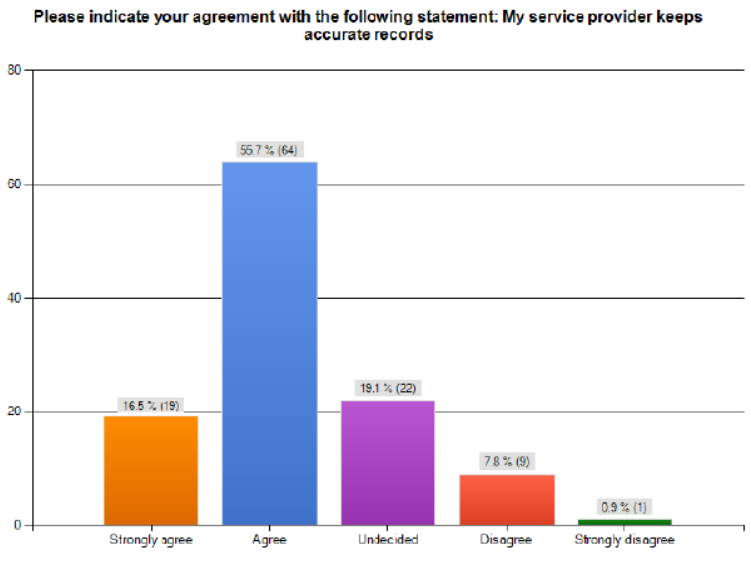

Figure 4.24: Chart showing whether service provider keeps accurate record or not

It was revealed from figure 4.23 above that $55.7 \%$ of 115 respondents agreed that their service provider keeps accurate records and just $7.8 \%$ disagreed to the statement.

Q13. Responsiveness

Please indicate your agreement with the following statements:

\begin{tabular}{|l|c|c|c|c|c|c|}
\hline Answer options & $\begin{array}{c}\text { Strongly } \\
\text { agree }\end{array}$ & Agree & Undecided & Disagree & $\begin{array}{c}\text { Strongly } \\
\text { disagree }\end{array}$ & $\begin{array}{c}\text { Response } \\
\text { count }\end{array}$ \\
\hline $\begin{array}{l}\text { Service provider } \\
\text { informs customer } \\
\text { exactly when } \\
\text { services will be } \\
\text { performed }\end{array}$ & 34 & 55 & 16 & 9 & 1 & 115 \\
\hline $\begin{array}{l}\text { Employees give } \\
\text { prompt services } \\
\text { to customers }\end{array}$ & 28 & 55 & 23 & 8 & 1 & 115 \\
\hline $\begin{array}{l}\text { Employees are } \\
\text { always willing to } \\
\text { help customers }\end{array}$ & 32 & 46 & 28 & 8 & 1 & 115 \\
\hline $\begin{array}{l}\text { Employees are } \\
\text { never too busy to } \\
\text { respond to } \\
\text { customers } \\
\text { request }\end{array}$ & 25 & 42 & 35 & 10 & 3 & 115 \\
\hline
\end{tabular}


Volume 3, Issue 1, 2016

\begin{tabular}{|l|l|c|}
\hline & Answered question & 115 \\
\hline & Skipped question & 0 \\
\hline
\end{tabular}

Figure 4.25: Table for the dimension-Responsiveness

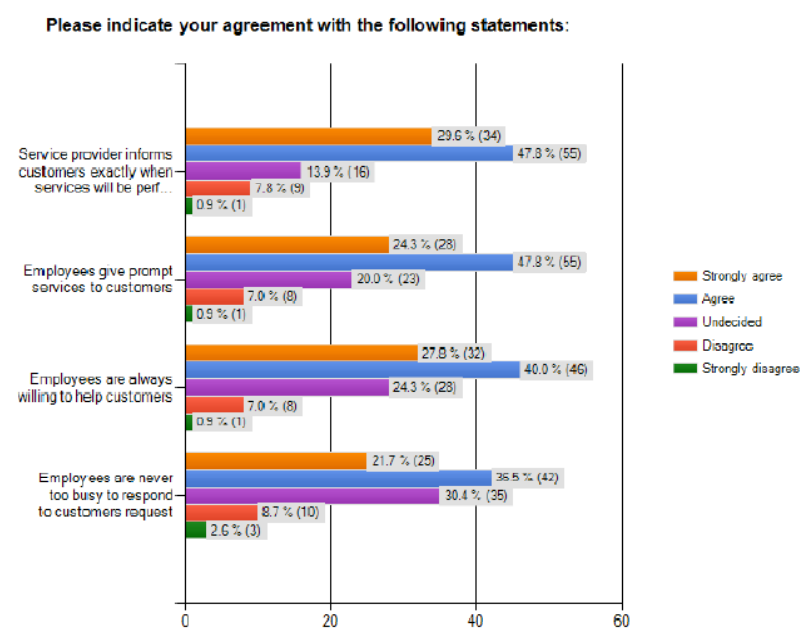

Figure 4.26: Chart for the dimension-Responsiveness

The service quality dimension 'responsiveness' from figure 4.26 above comprises of four items tailored towards measuring customer satisfaction from mobile phone providers.

Question 1: Service provider informs customers exactly when services will be performed: $47.8 \%$ agreed to that and $7.8 \%$ disagreed. The result equally revealed that $29.6 \%$ are even strongly in agreement but only $0.9 \%$ strongly disagreed.

Question 2: Employees give prompt services to customers: $47.8 \%$ agreed to this statement while $7.0 \%$ disagreed. $24.3 \%$ strongly agreed to that and just $0.9 \%$ strongly disagreed.

Question 3: Employees are always willing to help customers: $40.0 \%$ agreed to this and $7.0 \%$ disagreed. It is worthy of note that $27.8 \%$ strongly agreed that employees are always willing to help while $0.9 \%$ strongly disagreed.

Question 4: Employees are never too busy to respond to customers' request: $36.5 \%$ agreed to this statement and $8.7 \%$ disagreed. In the same vein, $21.7 \%$ strongly agreed to that and $2.6 \%$ strongly disagreed.

Q14. Assurance

\begin{tabular}{|l|c|c|c|c|c|c|}
\hline Answer options & $\begin{array}{l}\text { Strongly } \\
\text { agree }\end{array}$ & Agree & Undecided & Disagree & $\begin{array}{c}\text { Strongly } \\
\text { disagree }\end{array}$ & $\begin{array}{c}\text { Response } \\
\text { count }\end{array}$ \\
\hline $\begin{array}{l}\text { The behaviour of } \\
\text { employees instils } \\
\text { confidence in } \\
\text { customers }\end{array}$ & 27 & 58 & 23 & 7 & 0 & 115 \\
\hline $\begin{array}{l}\text { Customers' service } \\
\text { requests are duly } \\
\text { followed up }\end{array}$ & 15 & 56 & 29 & 13 & 2 & 115 \\
\hline $\begin{array}{l}\text { Employees providing } \\
\text { services are polite and } \\
\text { respectful }\end{array}$ & 30 & 51 & 24 & 8 & 2 & 115 \\
\hline $\begin{array}{l}\text { Employees in my } \\
\text { service provider are } \\
\text { knowledgeable } \\
\text { enough to answer } \\
\text { customers' questions }\end{array}$ & 29 & 53 & 23 & 9 & 1 & 115 \\
\hline
\end{tabular}




\begin{tabular}{|l|l|c|}
\hline & Answered question & 115 \\
\hline & Skipped question & 0 \\
\hline
\end{tabular}

Figure 4.27: Table for dimension-Assurance

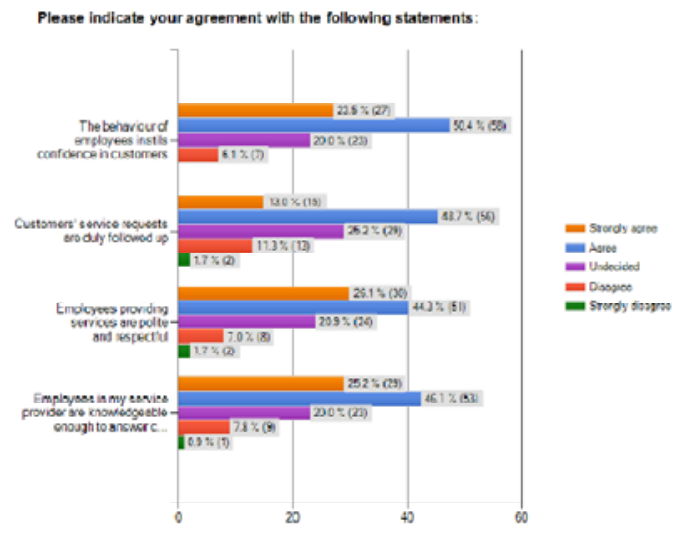

Figure 4.28: Chart for dimension-Assurance

The service quality dimension 'Assurance' from figure 4.28 above comprises of four items. These questions are structured to unmask the level of satisfaction customers get from mobile providers.

Question 1: The behaviour of employees instils confidence in customers: $50.4 \%$ believed in this statement and $6.1 \%$ disagreed. $23.5 \%$ strongly agreed while none of the respondents strongly disagreed to the statement.

Question 2: Customers' service requests are duly followed up: $48.7 \%$ were in agreement with the statement while $11.3 \%$ disagreed. $13.0 \%$ strongly agreed and just $1.7 \%$ strongly disagreed with the statement.

Question 3: Employees providing services are polite and respectful: $44.3 \%$ agreed to this statement while $7.0 \%$ disagreed, with $26.1 \%$ in strong agreement and $1.7 \%$ in strong disagreement with the statement.

Question 4: Employees in my service provider are knowledgeable enough to answer customer's questions: while $46.1 \%$ agreed with the statement, $7.8 \%$ disagreed, with $25.2 \%$ strongly in agreement and $0.9 \%$ strongly in disagreement.

Q15. Empathy

\begin{tabular}{|l|c|c|c|c|c|c|}
\hline Answer options & $\begin{array}{l}\text { Strongly } \\
\text { agree }\end{array}$ & Agree & Undecided & Disagree & $\begin{array}{c}\text { Strongly } \\
\text { disagree }\end{array}$ & $\begin{array}{c}\text { Response } \\
\text { count }\end{array}$ \\
\hline $\begin{array}{l}\text { My provider gives } \\
\text { individual attention } \\
\text { to customers }\end{array}$ & 28 & 59 & 20 & 7 & 1 & 115 \\
\hline $\begin{array}{l}\text { Employees in my } \\
\text { service provider } \\
\text { understand specific } \\
\text { needs of their } \\
\text { customers }\end{array}$ & 27 & 47 & 28 & 12 & 1 & 115 \\
\hline $\begin{array}{l}\text { My service provider } \\
\text { has customers best } \\
\text { interest at heart }\end{array}$ & 15 & 32 & 47 & 14 & 6 & 115 \\
\hline & & & & & 115 \\
\hline
\end{tabular}

Figure 4.29: Table for dimension-Empathy 


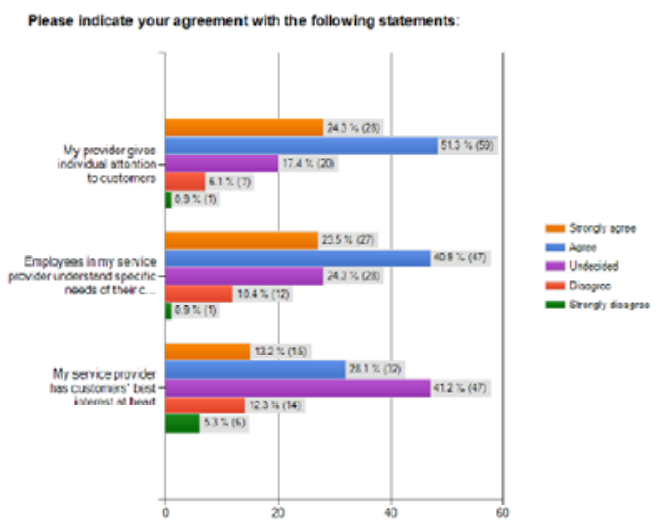

Figure 4.30: Chart for dimension-Empathy

The service quality dimension 'Empathy' from figure 4.30 above comprises of three items. These items will measure customers' perception of service from the mobile phone providers.

Question 1: My provider gives individual attention to customers: $51.3 \%$ agreed with the statement while $6.1 \%$ disagreed. $24.3 \%$ are in strong agreement and only $0.9 \%$ in strong disagreement.

Question 2: Employees in my service provider understand specific needs of their customers: while $40.9 \%$ were in agreement, $10.4 \%$ disagreed with the statement. $23.5 \%$ were in strong agreement and $0.9 \%$ in strong disagreement.

Question 3: My service provider has customers' best interest at heart: $28.1 \%$ agreed with this statement while $12.3 \%$ disagreed, with $13.2 \%$ strongly in agreement and 5.3\% strongly in disagreement.

Q16. Network Aspect

\begin{tabular}{|l|c|c|c|c|c|c|}
\hline Answer options & $\begin{array}{c}\text { Strongly } \\
\text { agree }\end{array}$ & Agree & Undecided & Disagree & $\begin{array}{c}\text { Strongly } \\
\text { disagree }\end{array}$ & $\begin{array}{c}\text { Response } \\
\text { count }\end{array}$ \\
\hline $\begin{array}{l}\text { My service providers' } \\
\text { network has excellent } \\
\text { voice quality }\end{array}$ & 9 & 37 & 21 & 39 & 9 & 115 \\
\hline $\begin{array}{l}\text { My service provider } \\
\text { has wider network } \\
\text { coverage }\end{array}$ & 8 & 36 & 12 & 41 & 18 & 115 \\
\hline $\begin{array}{l}\text { There are no call } \\
\text { drops in my service } \\
\text { provider }\end{array}$ & 6 & 22 & 24 & 40 & 23 & 115 \\
\hline & & & & Answered question & 115 \\
\hline
\end{tabular}

Figure 4.31: Table for dimension-Network aspect 
South American Journal of Management

Special Edition 2016

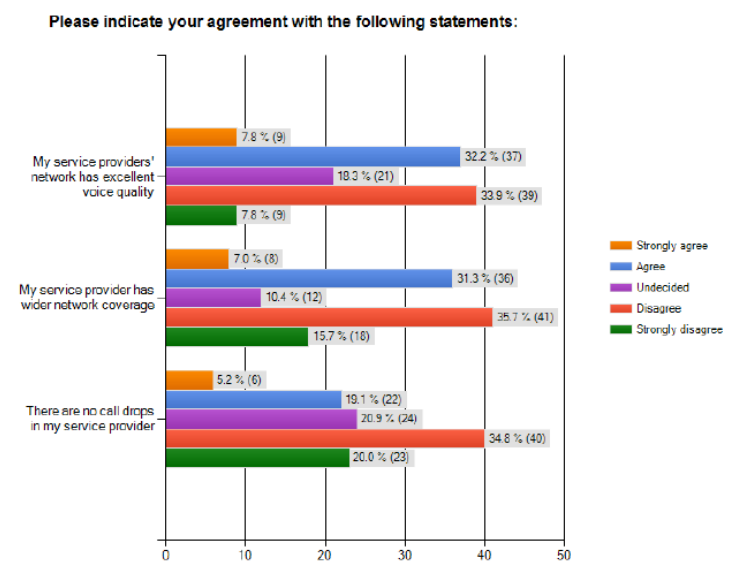

Figure 4.32: Chart for dimension-Network aspect

The service quality dimension 'Network aspect' from figure 4.32 above comprises of three items

These items will measure customers' perception of service and their loyalty to the mobile phone providers.

Question 1: My service providers' network has excellent voice quality: Interestingly, $32.2 \%$ of respondents agreed to the statement while $33.9 \%$ disagreed. $7.8 \%$ strongly agreed and $7.8 \%$ strongly disagreed.

Question 2: My service provider has wider network coverage: The percentage of respondents that agreed to the statement was $31.3 \%$ while $35.7 \%$ disagreed. $7.0 \%$ strongly agreed and $15.7 \%$ strongly disagreed.

Question 3: There are no call drops in my service provider: 19.1\% agreed to this statement while $34.8 \%$ disagreed, with $5.2 \%$ strongly in agreement and $20.0 \%$ strongly in disagreement.

Q17. Convenience

\begin{tabular}{|l|c|c|c|c|c|c|}
\hline Answer options & $\begin{array}{c}\text { Strongly } \\
\text { agree }\end{array}$ & Agree & Undecided & Disagree & $\begin{array}{c}\text { Strongly } \\
\text { disagree }\end{array}$ & $\begin{array}{c}\text { Response } \\
\text { count }\end{array}$ \\
\hline $\begin{array}{l}\text { My service provider } \\
\text { has sufficient offices } \\
\text { in different parts of } \\
\text { Ireland }\end{array}$ & 33 & 46 & 22 & 10 & 4 & 115 \\
\hline $\begin{array}{l}\text { My service provider } \\
\text { has toll-free/low cost } \\
\text { numbers, websites, etc } \\
\text { for clarification of } \\
\text { problems \& checking } \\
\text { a/c status by customers }\end{array}$ & 30 & 53 & 17 & 14 & 1 & 115 \\
\hline $\begin{array}{l}\text { It's easy to pay bill to } \\
\text { my service provider }\end{array}$ & 33 & 54 & 14 & 12 & 2 & 115 \\
\hline $\begin{array}{l}\text { The opening hours in } \\
\text { my service provider } \\
\text { are convenient to } \\
\text { customers. }\end{array}$ & 20 & 58 & 18 & 15 & 3 & 115 \\
\hline \multicolumn{2}{|l|}{} & & & & Answered question & 115 \\
\hline
\end{tabular}

Figure 4.33: Table for dimension-Convenience 


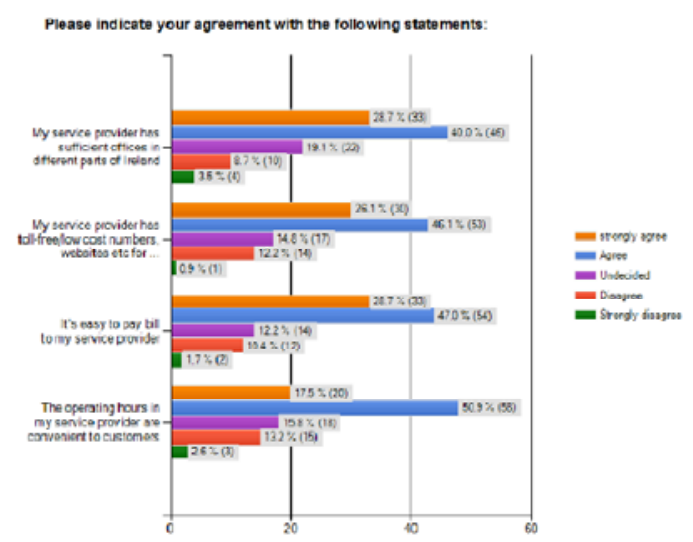

Figure 4.34: Chart for dimension-Convenience

The service quality dimension 'Convenience' from figure 4.34 above comprises of four items

These items will measure customers' perception of service from the mobile phone providers.

Question 1: My service provider has sufficient offices in different parts of Ireland: $40.0 \%$ agreed to this statement and $8.7 \%$ disagreed. On the other hand, while $28.7 \%$ strongly agreed, only $3.5 \%$ strongly disagreed.

Question 2: My service provider has toll-free/low cost numbers, websites etc for clarification of problems \& checking accounts status by customers: $46.1 \%$ of the respondents agreed to this statement while $12.2 \%$ disagreed. $26.1 \%$ strongly agreed and just $0.9 \%$ strongly disagreed

Question 3: It's easy to pay bill to my service provider: $47.0 \%$ agreed while $10.4 \%$ disagreed to the statement. In the same vain $28.7 \%$ strongly agreed and $1.7 \%$ strongly disagreed.

Question 4: The operating hours in my service provider are convenient to customers: while $50.9 \%$ of the respondents agreed to this statement, $13.2 \%$ disagreed. $17.5 \%$ on the other hand strongly agreed and just $2.6 \%$ strongly disagreed.

Q18. Loyalty

\begin{tabular}{|c|c|c|c|c|c|c|}
\hline Answer options & $\begin{array}{c}\text { Strongly } \\
\text { agree }\end{array}$ & Agree & Undecided & Disagree & $\begin{array}{l}\text { Strongly } \\
\text { disagree }\end{array}$ & $\begin{array}{l}\text { Response } \\
\text { count }\end{array}$ \\
\hline $\begin{array}{l}\text { I will continue using } \\
\text { this service provider }\end{array}$ & 17 & 32 & 27 & 33 & 6 & 115 \\
\hline $\begin{array}{l}\text { Even when I want to } \\
\text { have more } \\
\text { connections, I will } \\
\text { stick to my service } \\
\text { provider }\end{array}$ & 14 & 20 & 31 & 37 & 13 & 115 \\
\hline $\begin{array}{l}\text { No matter the cost of } \\
\text { using other providers, } \\
\text { I will continue using } \\
\text { my current provider }\end{array}$ & 4 & 18 & 34 & 37 & 22 & 115 \\
\hline $\begin{array}{l}\text { I will surely } \\
\text { recommend my } \\
\text { service provider to } \\
\text { friends/relatives }\end{array}$ & 7 & 27 & 28 & 26 & 26 & 115 \\
\hline \multicolumn{6}{|c|}{ Answered question } & 115 \\
\hline & & & & \multicolumn{2}{|c|}{ Skipped question } & 0 \\
\hline
\end{tabular}


South American Journal of Management

Special Edition 2016

Figure 4.35: Table for dimension-Loyalty

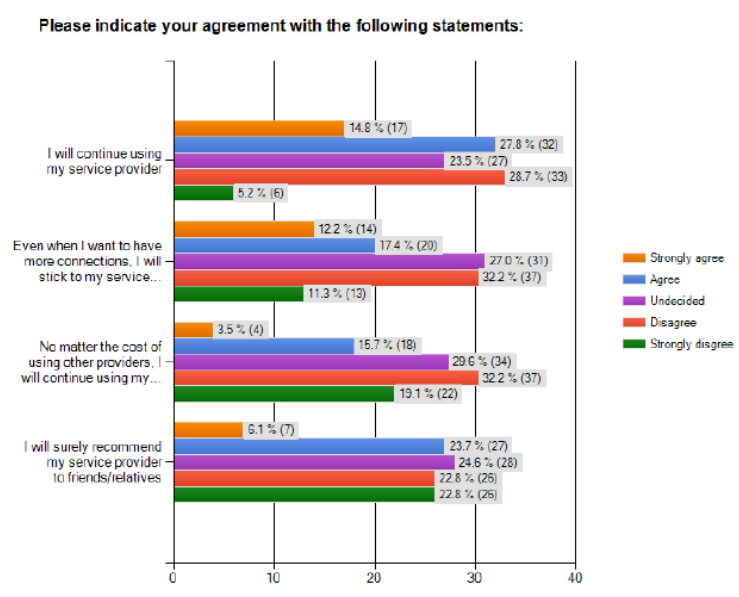

Figure 4.36: Chart for dimension-Loyalty

The service quality dimension 'Loyalty' from figure 4.36 above comprises of three items

These items will measure customers' perception of service and their loyalty to the mobile phone providers.

Question 1: I will continue using this service provider: Interestingly, $27.8 \%$ of the respondents agreed to this statement while $28.7 \%$ disagreed. $14.8 \%$ strongly agreed and $5.2 \%$ strongly disagreed.

Question 2: Even when I want to have more connections, I will stick to my service provider: $17.4 \%$ agreed and $32.2 \%$ disagreed to this statement. $12.2 \%$ strongly agreed while $11.3 \%$ strongly disagreed.

Question 3: No matter the cost of using other providers, I will continue using my current provider: While $15.7 \%$ agreed to this statement, $32.2 \%$ disagreed with only $3.5 \%$ in strong agreement and $19.1 \%$ in strong disagreement.

Question 4: I will surely recommend my service provider to friends/relatives: $23.7 \%$ were in agreement with the statement and $22.8 \%$ in disagreement. In the same vain $6.1 \%$ strongly agreed and $22.8 \%$ strongly disagreed.

Q19. Pricing

\begin{tabular}{|l|l|l|l|l|l|l|}
\hline Answer options & $\begin{array}{l}\text { Strongly } \\
\text { agree }\end{array}$ & Agree & Undecided & Disagree & $\begin{array}{l}\text { Strongly } \\
\text { disagree }\end{array}$ & $\begin{array}{l}\text { Response } \\
\text { count }\end{array}$ \\
\hline $\begin{array}{l}\text { The prices of } \\
\text { phones/tariffs and } \\
\text { other products \& } \\
\text { services in my } \\
\text { service provider are } \\
\text { affordable }\end{array}$ & 8 & 36 & 25 & 36 & 10 & 115 \\
\hline $\begin{array}{l}\text { It's easy to } \\
\text { understand the prices } \\
\text { in my service } \\
\text { provider }\end{array}$ & 11 & 29 & 14 & 47 & 14 & 115 \\
\hline $\begin{array}{l}\text { The prices in my } \\
\text { service provider are } \\
\text { competitive }\end{array}$ & 8 & 30 & 25 & 31 & 21 & 115 \\
\hline $\begin{array}{l}\text { I am happy with the } \\
\text { prices in my service } \\
\text { provider }\end{array}$ & 6 & 29 & 18 & & 43 & 17 \\
\hline
\end{tabular}




\begin{tabular}{|l|l|l|}
\hline & Skipped question & 0 \\
\hline
\end{tabular}

Figure 4.37: Table for dimension-Pricing

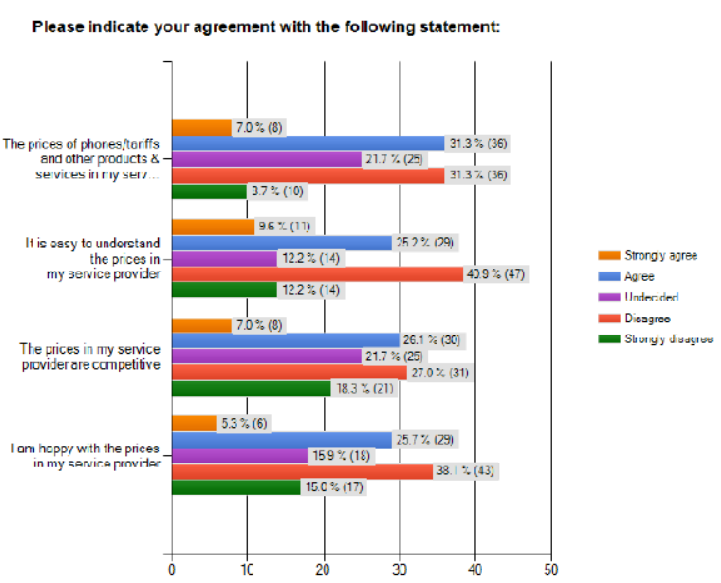

Figure 4.38: Chart for dimension-Pricing

The service quality dimension 'Pricing' from figure 4.38 above comprises of four items

These items will measure customers' perception of service and their loyalty to the mobile phone providers.

Question 1: The prices of phones/tariffs and other products and services in my service provider are affordable: $31.3 \%$ of the respondents agreed to this statement while exactly same $31.3 \%$ disagreed. $7.0 \%$ strongly agreed and $8.7 \%$ strongly disagreed.

Question 2: It's easy to understand the prices in my service provider: $25.2 \%$ were in agreement with this statement and $40.9 \%$ in disagreement. In the same vain $9.6 \%$ strongly agreed while $12.2 \%$ strongly disagreed.

Question 3: The prices in my service provider are competitive: $26.1 \%$ agreed while $27.0 \%$ disagreed. On the other hand, $7.0 \%$ strongly agreed and $18.3 \%$ strongly disagreed.

Question 4: I am happy with the prices in my service provider: $25.7 \%$ of the respondents agreed to this statement and $38.1 \%$ disagreed. $5.3 \%$ strongly agreed while $15.0 \%$ strongly disagreed.

\section{Interpretation: cross-tabulation of research findings}

Cross tabulation which is interchangeably used as contingency table or composite score is defined as a technique for summarising data from two or more variables so that specific values can be read (Saunders et al., 2007) Paul Szwarc (2005) argued that many customer satisfaction and loyalty surveys these days use cross tabulation for tracking and reporting their results. These cross tabulation is based on a combination of results from several questions. He went further to say that it therefore contains data about current perceptions of service, advocacy and loyalty (where loyalty is represented as future purchase intention. Customers who perceive higher levels of service quality (and satisfaction) will demonstrate greater commitment to the organisation and therefore repurchase behaviour and loyalty Fornell (1992); Steenkamp (1989); Boulding et al. (1993). However, as with the word 'quality', the meaning of satisfaction has evolved to imply gratification and fulfilment (Gabbott, M. and Hogg, G. 1988). See also 2.2.1

The researcher believes that mere asking a customer whether he is satisfied with the services from a service provider is simply a tip of the iceberg and wallows in ambiguity. This is because the researcher is of the opinion that several factors may determine how satisfied a customer is, hence the use of cross tabulation of relevant variables in proving and disproving the research hypotheses.

Customer perception of service in the tangibles dimension was positive as sizeable number of respondents indicated high level of satisfaction on the three items/questions; "do you think 
your service provider has up-to-date equipment"; "the physical facilities at my service provider are visually appealing"; "the employees at my service provider appear neat and well dressed". See 4.1.2, (Q6, Q7, Q8)

On the reliability dimension, the satisfaction derived by customers as highlighted in the findings (See 4.1.2- Q9, Q10, Q11, Q12) is a very positive one in comparison with the negative responses. Majority of the respondents accepted that their service providers are reliable and could be completely trusted. This positive response rating was based on the four items/questions: "my service provider delivers on its promises"; "my service provider shows a sincere interest in solving my problem"; "I trust my service provider"; "my service provider keeps accurate records".

\section{Cross tabulation of variables}

\section{Responsiveness dimension and Loyalty}

The relationship here between customer satisfaction using responsiveness dimension and loyalty yielded a positive result (see appendix 4).This rosy relationship was evident from strong customer loyalty using one question on loyalty "I will continue using this service provider". Customers' response clearly showed that from a total of four responsiveness questions asked, customers' loyalty was reasonably high.

\section{Assurance dimension and loyalty}

Customers' perception of service using assurance dimension with one loyalty question "I will continue using this service provider" is everything but pessimistic. There is a clear agreement based on the response that customers are satisfied with the services they receive from their providers (see appendix 5). A high percentage of respondents agreed that they would continue using their providers based on the four questions asked.

\section{Empathy dimension and loyalty}

A high percentage of respondents (see appendix 6) expressed a strong agreement that the service they receive from their providers is good. This was based on the cross tabulation of the three questions from empathy dimension with loyalty. The loyalty question, "I will continue using this service provider" was used in the cross tabulation.

\section{Convenience dimension and loyalty}

There was a constructive optimism and confidence by respondents about the satisfaction they get from their mobile providers. A high number of respondents (see appendix 7) agreed that they will continue using their service providers based on the four questions asked.

H1: Customer satisfaction has a significant influence on loyalty.

Anderson and Sullivan (1993) argued that higher levels of customer satisfaction can lead to a reduction of the perceived benefits of alternative suppliers and hence to higher repurchase intentions. Johnson and Sirikit (2002) from their research equally found a link between satisfaction and loyalty when they argued that, service is a form of attitude which is related to satisfaction and also leads to consumer loyalty. From the analysis of relationships between variables above, the researcher has found out that the six dimensions (tangibles, reliability, Texila American University Page 94 responsiveness, assurance, empathy and convenience) when compared/cross-tabbed with loyalty showed a very positive result. This was very clear that when customers are satisfied, their level of loyalty increased. The above hypothesis was therefore supported by the research findings.

\section{Network aspect dimension and Loyalty}

Research findings have revealed that customers' perception of service has conspicuously changed from that of the previous six dimensions above. When the first question on network aspect was cross tabulated with the loyalty item, "I will continue using this service provider", there was a 50/50 response. The cross tabulation of the second question on network aspect 
with same loyalty question was positive because slightly more respondents agreed that they will keep using the service provider. When the third question on same network aspect was cross tabulated with the same loyalty item, it was negative because a higher number of respondents disagreed with the statement (See appendix 8)

From the research findings, the cross tabulation of the three questions on network aspect with the loyalty item, "Even when I want to have more connections, I will stick to my service provider" showed an interesting result (see appendix 8, 2nd table). All the three questions got negative responses. This means that respondents were not satisfied and disagreed with the statement. Also the cross tabulation of the three questions on network aspect with loyalty item, "no matter the cost of using other providers, I will continue using my current provider" (see appendix 8,3rd table) equally showed that respondents were dissatisfied on the three questions. The research findings also disclosed that the cross tabulation of the three questions on network aspect with the loyalty item, "I will surely recommend my service provider to friends/relatives showed that: firstly, though more respondents agreed to the statement on the three questions, it should be noted that the difference between the agreement and disagreement was very infinitesimal. Secondly, this means that a reasonable number of respondents were also dissatisfied. (see figure appendix 8, 4th table).

$\mathrm{H} 2$ : The higher the perceived network quality, the greater the level of loyalty from customers.

The research findings revealed that the higher the perceived network quality, the greater the level of loyalty (positive effect) on just two of the loyalty items "I will continue using this service provider", and "I will surely recommend my service provider to friends/relatives". The two remaining items of loyalty, "Even when I want to have more connections, I will stick to my service provider", and "No matter the cost of using other providers, I will continue using my current provider" did not support the hypothesis. This means that the findings on the perceived network quality have a negative effect on these two items. Based on the above, the researcher could neither support nor disprove the hypothesis.

\section{Pricing dimension and Loyalty}

The perception of price has a positive effect on one loyalty item, "I will surely recommend my service provider to friends/relatives" (see appendix 9, 4th table) but on the other hand, it has a negative effect on one loyalty item, "Even when I want to have more connections, I will stick to my service provider". (see appendix 9,2nd table) The perception of price on the other two loyalty items, "I will continue using this service provider", and "No matter the cost of using other providers, I will continue using my current provider", is neither positive nor negative. (see appendix 9, 1st and 3rd table respectively).

H3: Price has a significant influence on customers' perception of service from mobile providers in Ireland.

A link between price and customer perception of service was highlighted by Kollmann, (2000). Price according to him plays a vital role in telecommunication market especially for the mobile telecommunication service providers. He further argued that generally, price includes not only the purchase price but also the call and rental charges. A price dominated mass market leads to customers having more choice and the opportunity to compare the pricing structures of different providers. Therefore, the company that will offer lower charges, the more customers will commit themselves to the telephone networks, so more call minutes will be achieved (Kollmann, 2000). Hence from the findings, the researcher gathered that price has a significant influence on customers' perception of service from mobile providers in Ireland on two items as mentioned above (both positive \& negative effect). The hypothesis is therefore partially supported within the mobile phone providers in Ireland. 
South American Journal of Management

Special Edition 2016

\section{Conclusions and Recommendations/Limitations}

\section{Conclusion and recommendations}

Although there are five major players in the Irish mobile phone market, (Vodafone, Meteor, 3 Network, E-mobile and Tesco- i.e. after the acquisition of Telefonica-O2 Ireland by 3 -Network) the competition between them is more intense than ever. They compete not only in network quality by a large amount of investment in network extension and upgrading, but also in customer retention and acquisition by direct and indirect price reduction. Since the mobile phone market in Ireland is close to saturation point, continued innovation is vital to ensure market growth. This innovation is equally essential in the improvement of service quality.

The primary objective of this research is to explore the expectations and perceptions of service that customers receive from mobile phone providers in Ireland. The focus of this research work is to identify service quality gap(s) using nine modified SERVQUAL dimensions. To measure this service quality a five-point Likert type scale was used ranging from strongly agree, agree, undecided, disagree and strongly disagree. These nine dimensions are: tangibles, reliability, responsiveness, assurance, empathy, convenience, network aspect, loyalty and pricing.

The research findings have shown that six out of the nine dimensions, specifically, tangibles, reliability, responsiveness, assurance, empathy and convenience which have a total of 22 items/questions performed comparatively well in terms of achieving customer satisfaction. 21 out of these 22 items all scored above $50 \%$, in their customer satisfaction rating (i.e. using 'agree' merged with 'strongly agree' scale) with just one item under empathy scoring below $50 \%$. The remaining three dimensions of network quality, loyalty and pricing (with a total of 11 items/questions) all scored poorly and in some cases very poorly in the customer satisfaction rating. This means that customers are not satisfied with the level of service they received from these three dimensions.

One of the research objectives is 'to explore the differences between expected and perceived service as experienced by users and to identify the service quality gaps using the modified SERVQUAL dimensions'. As mentioned above, a very high percentage of respondents were dissatisfied with the perceived service quality in terms of loyalty, network aspect and pricing. In other words, a very low percentage was satisfied therefore making the service quality gap wider. The research findings revealed that the highest quality gap was reported with these three dimensions. Another research objective is 'to critically examine the effect of customer satisfaction on loyalty and retention'. Research findings showed that loyalty level was high when customers were satisfied with the service quality like on the six dimensions mentioned above. On the other hand, when the 'loyalty dimension' was cross tabbed with the items in the remaining dimensions of network aspect and pricing, the result clearly showed that customer satisfaction has a significant effect on loyalty. This is because loyalty level was very low as a result of poor customer satisfaction received by customers.

Overall, $56.09 \%$ of the respondents from the nine dimensions were satisfied with the services received from mobile providers, while $22.67 \%$ were dissatisfied leaving $21.24 \%$ undecided. This calculation was made firstly from getting the average percentage from the 33 items/questions merging 'agree' and 'strongly agree' to give $56.09 \%$. The same parameter was used by merging 'disagree' and 'strongly disagree' to get $22.67 \%$. The researcher is strongly of the opinion based on the findings that customers' perception of service depends on the quality of service

The researcher also recommends that though the nine dimensions of SERVQUAL used in this research are vital in measuring service quality, network quality is one of the most important drivers of the overall service quality. Service providers should as a matter of priority pay more emphasis on that and the researcher recommends network sharing by operators as a way to improve coverage for mobile phone users. Irish republic should open more doors to allow more foreigners to invest in the telecommunication industry. This 
according to the researcher will not only create jobs but will also create an avenue for a healthy competition which in-turn leads to service improvements. The researcher is of the opinion that mobile providers in Ireland should not be divorced from the communication realities of the contemporary society. The mobile providers can achieve this by making policies and formulating strategies that are aimed at promoting and improving service quality in all ramifications. The researcher equally recommends that mobile providers in Ireland should carry out market research frequently in order to ascertain what customers need.

\section{Research Limitations and Future Directions}

One of the limitations in this research is that the questionnaire did not take into consideration the cultural variable of measuring customer behaviour intentions as highlighted by De Mooij, (2004). He noted that different value orientations cause variations in preferences for products and brands and that, values of both consumers and marketers are defined by their culture. (See 3.9.5 for reasons for not including culture). Due to time constraint for writing this research work, the researcher didn't contact as many participants as planned for the pilot survey and this might affect the true representation. The researcher also discovered that most of the secondary data for research literature weren't updated.

Also, since two of the three hypotheses tested are not strongly supported by the research findings, additional research which should examine the three dimensions of network aspect, loyalty and pricing is needed. This should examine these dimensions and the relationships with service quality in the Irish mobile industry. However, the modified SERVQUAL instrument used in the research is found to be dependable in measuring service quality of mobile telecommunications industry in Ireland.

\section{Self Reflection On Own Learning Performance}

The purpose of this chapter is not only to outline the whole learning process (s) applied by the researcher during the course of carrying out this research work but also to explore them. As research work is normally rigorous, the researcher will examine the challenges he encountered during this process. The researcher based on his internal thoughts, will convey the information involved in data collation and analysis in a written report which will inevitably contribute to future growth and development.

\section{Learning styles}

Learning style is a component of the wider concept of personality and there are fiveprinciple model of the whole person that encompasses evolutionary design for human nature, dispositional traits, characteristic adaptations, self-defining life narratives, and culture/social contexts. Learning style falls into the categories of dispositional traits and characteristic adaptations where there are differences across individual humans but there are groupings of humans who have common or similar learning style characteristics (Mc Adams and Pals 2006). Advocates of learning style models (Claxton \& Murrell, 1987; Coffield et al., 2004a, b) postulate that students learn in different ways.

Among the well-known and widely available learning style instruments is the one offered by David Kolb. Kolb published his learning style model in 1984 and this model gave rise to related terms such as Kolb's experimental learning theory (ELT), and Kolb's learning styles inventory (LSI). This experimental model defines learning as "the process whereby knowledge is created through the transformation of experience". Learning is a holistic set of processes that are continuous, with a lesser emphasis on outcomes. Learning style is the "generalised differences in learning orientation based on the degree to which people emphasize the four modes of the learning process" (David Kolb, 1984).

The model asserts a four-mode or four-process learning cycle that covers and generally starts with Concrete Experience (CE), moving to Reflective Observation (RO), then to Abstract Conceptualization (AC), and finally to Active Experimentation (AE). Kolb includes this 'cycle of learning' as a central principle in his experiential learning theory, typically 
expressed as four-stage cycle of learning, in which 'immediate or concrete experiences' provide a basis for 'observations and reflections'. These 'observations and reflections' are assimilated and distilled into 'abstract concepts' producing new implications for action which can be 'actively tested' in turn creating new experiences. Kolb says that ideally (and by inference not always) this process represents a learning cycle or spiral where the learner 'touches all the bases', i.e. a cycle of experiencing, reflecting, thinking, and acting. Immediate or concrete experiences lead to observations and reflections.

The researcher's research voyage spiralled and touched all the bases as mentioned above. This is because the researcher's pool of academic, professional knowledge supported by his general life experiences before the postgraduate programme (which is a subset of his concrete experience) have culminated into a natural flow pattern of 'concrete experience', 'reflective observation', 'abstract conceptualization', and 'active experimentation'.

Kolb (1984) argued that everyone responds to and needs the stimulus of all types of learning styles to one extent or another - it's a matter of using emphasis that fits best with the given situation and a person's learning style preferences. He identified four learning styles:

Diverging learning style: These people are able to look at things from different perspectives. They are sensitive. They prefer to watch rather than do, tending to gather information and use imagination to solve problems. They are best at viewing concrete situations in several different viewpoints. They have broad cultural interest.

Assimilating learning style: The Assimilating learning preference is for a concise, logical approach. Ideas and concepts are more important than people. These people require good clear explanation rather than practical opportunity. People with this style are more attracted to logically sound theories than approaches based on practical value.

Converging learning style: People with a Converging learning style can solve problems and will use their learning to find solutions to practical issues. They prefer technical tasks, and are less concerned with people and interpersonal aspects. People with a Converging learning style are best at finding practical uses for ideas and theories. They can solve problems and make decisions by finding solutions to questions and problems.

Accommodating learning style: The Accommodating learning style is 'hands-on', and relies on intuition rather than logic. These people use other people's analysis, and prefer to take a practical, experiential approach. They are attracted to new challenges and experiences, and to carrying out plans. The figure below illustrates Kolb's learning model

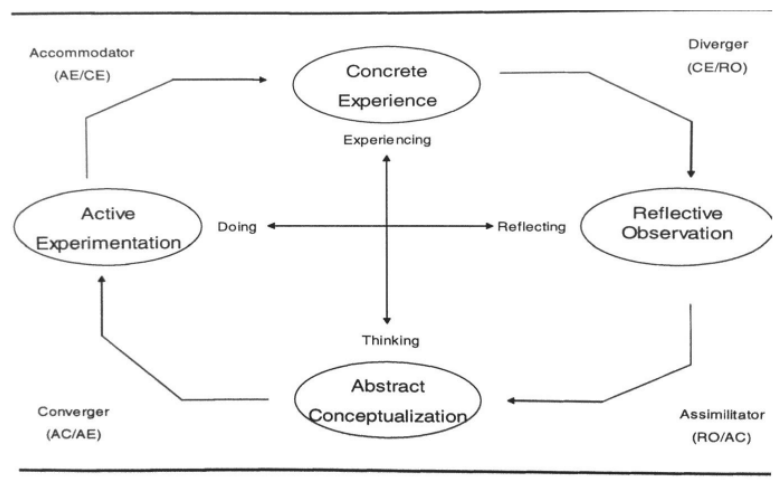

Figure 6.1: Kolb's experiential learning model

Source: Hawk, T.F. and Shah, A.J (2007)

Honey and Mumford (1992) are among many who have built on this theory to inform training and learning design. Their learning styles inventory (LSI) identifies four main types of learner and of learning style-Activist, Reflector, Analyst and Pragmatist- and links them to the four stages of Kolb's learning cycle.

- Activists- 'here and now', gregarious, seeks challenge and immediate experience, open-minded, bored with implementation 
- Reflectors-'stand back', gather data, ponder and analyse, delay reaching conclusions, listen before speaking, thoughtful

- Theorists- think things through in logical steps, assimilate disparate facts into coherent theories, rationally objective, reject subjectivity and flippancy

- Pragmatists- seek and try out new ideas, practical, down-to-earth, enjoy problem solving and decision-making quickly, bored with long discussions

There is arguably a strong similarity between the Honey and Mumford styles/stages and the corresponding Kolb learning styles. Honey and Mumford used different words to describe the stages of the learning cycle as follows:

Activist $=$ Accommodating i.e. Active Experimentation

Reflector $=$ Diverging i.e. Reflective Observation

Theorist $=$ Assimilating i.e. Abstract Conceptualisation

Pragmatist $=$ Converging i.e. Concrete Experience

From the above, the new improved Kolb's learning styles are illustrated thus:

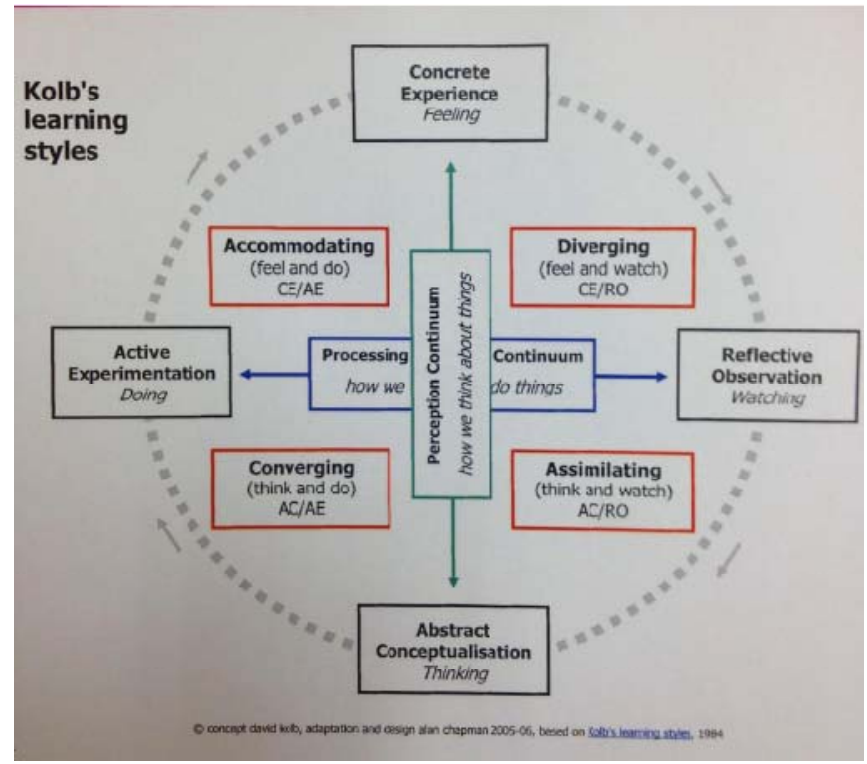

Figure 6.2: Kolb's learning styles

\section{SOURCE: http://www.businessballs.com/kolblearningstyles.htm}

As a pragmatist and an active learner, the researcher has used this learning style to find practical uses for ideas and theories. The researcher as a pragmatist simply means that he likes to experiment with new ideas, to simulate, and to work with practical applications. This learning style equally enables the researcher to solve problems and make decisions by finding solutions to questions and problems. By using the learning style questionnaire developed by Honey and Mumford (1986), the researcher was able to find out the most likely learning style that suits him. This pragmatic style of the researcher is reminiscent to the converging style which was developed by David Kolb (1984)

\section{Researcher's self assessment}

\section{Educational Background-The Undergraduate Degree}

My graduation from secondary school was seen as a turning point in my life due to the envisaged challenges. The elasticity of my passion for Finance and Accounting grows to infinity and my appetite for continuous learning was unquenchable. In order to develop my analytical skills that will propel me into the future, I enrolled at the Enugu State University of Science \& Technology, Enugu, Nigeria where I earned a bachelor's degree in Finance. Nigeria is an ethnically diversified country and the cultural mix in the college gave me the opportunity to interact with people from different cultural and ethnic background. 
Hofstede (1997, p.5), defines culture as "the collective programming of the mind which distinguishes the members of one group from another". De Mooij, M (2004) argued that the concept of collectivism (where priorities are given to harmony, conformity, and close relationships within groups) is characteristic of Asia, much of South America and Africa. In this University, I was always providing my team members with ideas. I acquired some statistical, mathematical, technical and creative thinking skills after graduation which was of immense benefits.

My burning desire for exposure to the international business arena was inextinguishable. In order to accomplish this desire, I moved to Ireland and enrolled at Limerick Senior College where I earned a diploma in Manual \& Computerised Accounting (where I was opportune to acquire basic presentation skills); and also certificate in Insurance from Insurance Institute of Ireland. The researcher is also a Master's degree holder in Business Management from Liverpool John Moores University, United Kingdom.

\section{Professional Background}

I had several jobs after my undergraduate degree before going back for my postgraduate education. I worked as a: Finance officer in the FCDA, Abuja, Nigeria; Finance officer, Sheraton Hotel Abuja; Management consultant, Malpac Nigeria Ltd, Abuja; Manager, NigerLinks Hotel, Abuja; Night Auditor, Clarion Hotel Limerick, Ireland; Assistant Night Manager, Hilton Hotel Limerick; Customer Care Executive, o2 Communications Ireland; Retail Executive, Telefonica-O2 Ireland. The slight shift in career was an offspring of my childhood passion of linking the world in one global village through telecommunication. In Telefonica-O2, I was responsible for reaching out to people and using my communication skills to negotiate and get new customers which obviously developed my personal strengths. (See appendix 11). My job has exposed me to some of the vital professional skills needed for success like the effective time management, customer retention and people management.

\section{Cognitive Business Management Skills}

Starting my postgraduate education in Liverpool John Moores University was simply a continuum of my business management knowledge which gives me joy. This decision was necessary in order to acquire an in depth business, technical and theoretical knowledge. Though as a pragmatist and also an active learner my theoretical knowledge wasn't low because of the human resources course I did in my undergraduate study. It also improved my critical thinking and analytical skills which will propel me towards achieving my professional ambition. Due to the avid interest I have for business management, I subscribed to some international financial magazines. This will enable me get first hand information and insight on the global business environment. I gained a lot of insights from the project management subject which I find very interesting as almost everything we do in business involves one type of project or the other. Although the start of my Master's degree was not a bed of roses but resilience coupled with unalloyed determination thrived.

\section{Critical Research Investigation Skills}

My undergraduate/postgraduate degree and professional experience exposed me to research and investigative methods. The need for critical evaluation of ideas with scholarly referencing ability is of paramount importance and will be of great help in my future endeavours. During my postgraduate education my critical research and investigation ability was enhanced with the help of my creative thinking. One of my strongest skills is creative thinking which I hope to apply through the course of achieving my professional ambition.

\section{Questionnaire design skill}

Questionnaires usually form an integral part of descriptive and opinion related surveys and its importance in research work cannot be overemphasised. The questionnaire design skill is undoubtedly essential in the collection of primary data especially in the analysis of data. 
Before the researcher started formulating questions to be included in a questionnaire, it became imperative to have clarity about the research question and intended objectives. The researcher also through the review of literature was able to find out the gaps in the research topic which obviously needed to be filled. The researcher observed that the only way to fill these gaps was to design an all-inclusive questionnaire that will provide answers to the research question (s).

The researcher prior to enrolling for the postgraduate programme had a minimal knowledge about different data collection techniques and the guiding research philosophy. The researcher has fully acquired this knowledge as a result of the research project. The critical review of literature done by the researcher and his creative thinking capability has added yet another academic arsenal to the researcher's skills portfolio.

\section{Data Analysis skill, Business Models and Management Tools}

Coming from a Finance background is undoubtedly a perfect combination in achieving my professional ambition. The above qualification and experience have given me the needed data analysis skills and financial management competence which is required to manage the accounts of a company. One of the modules I took in my postgraduate programme was project management which is also a big boost especially when setting-up a business. This project management module gave me the opportunity for an in depth understanding of "Activity Sequencing", including the determination of a critical path of a project via a network diagram which is vital in more complex projects in my career. During my postgraduate programme, I was exposed to the applicability of some marketing tools and models like Porter's Five Forces, the SWOT analysis (See appendix 11) and PESTEL. Especially now that businesses are going global, the risk of failure could be eliminated by effectively making use of these tools in analysing the market environment. Equally worthy of mention is the in-depth case study analysis which I was taught in the strategic management course.

\section{Inter-Personal Skill Development}

Focused, resilient, introverted and highly self-esteemed personality, are some of the major characteristics of the researcher's personality. Be that as it may, 'others can't be relied on' and 'insist on my view' characteristics will fall into the negative aspect of my personality. Leadership does not exist in vacuum but also involves a combination of other factors. In order to climb my leadership ladder successfully, I was determined to remove those cog in the wheel of my progress. This can only be achieved by improving these negative traits mentioned above. In my work place, I was given the responsibility of co-ordinating and briefing staff members on current events every week. As a role model, I took the bull by the horn and started relying on others and also taking in others views, because a tree cannot make a forest.

\section{Future Application of Learning}

Improvement is an unending ingredient of life which the researcher will keep doing through frequent evaluation of his performance. As said before, change is the only constant and the postgraduate programme has given me the necessary insight to learn and change. Life is about continuous improvement hence my target skills tend to infinity. I believe that there is always room for improvement in all endeavours and class work and individual assignments are no exception. My avid interest in book writing and information security will surely make me to expand my knowledge towards these areas. Life is all about moving with time and following the trend of events/issues.

Having successfully completed my Master's degree, with a wife and three children involves a lot of sacrifices and compromises. Being able to pass through academic rigours in combination with family life and work has made me tougher and ever ready for the challenges in future. My postgraduate education has provided me with enormous pool of skills and 
South American Journal of Management

Special Edition 2016

knowledge when making decisions and also to be critical in all spheres of life especially in business/management. I believe that the sky is my limit through lifelong and continuous improvement.

\section{Bibliography/References}

[1.] Anderson, E. W. and Sullivan, M. W. (1993) 'The antecedents and consequences of customer satisfaction for firms'. Marketing Science, 12 (2): 125-143.

[2.] Anderson, E.W. et al., (1994) 'Customer satisfaction, market share; and profitability: findings from Sweden'. Journal of Marketing, 58, January, p. 53-66.

[3.] Antonides, G. and Van Raaij, W.F. (1998) Consumer behaviour: A European perspective, Chichester, UK: John Wiley \& Sons, p 162-163.

[4.] Bagozzi, R.P. et al., (2002) The Social Psychology of Consumer Behaviour. Buckingham: Open University Press.

[5.] Beard, C. and Hartmann, R. (1999) 'European and Asian Telecoms: Their Role in Global Sustainable Development'. European Business Review, 99 (1): 42-54.

[6.] Bebko, P. (2000), 'Service intangibility and its impact on consumer expectations of service quality'. Journal of services marketing, 14(1): 9-26.

[7.] Belk, Russell W. (1984) 'Cultural and historical differences in concepts of self and their effects on attitudes toward having and giving: In advances in consumer research'. Association for consumer research, p 753-760.

[8.] Berry, L.L. and Parasuraman, A. (1991) Marketing Services, New York: Free Press

[9.] Bettencourt, L.A. and Gwinner, K. (1996) 'Customisation of the Service Experience: The Role of the Frontline Employee'. International Journal of Service Industry Management, 7 (2): 3-20

[10.] Blackwell, R. D. et al., (2000). Consumer behaviour. Howard: W. Sams \& Co.

[11.] Blery, E. et al., (2009) 'Service quality and customer retention in mobile telephony'. Journal of targeting, measurement $\&$ analysis for marketing, 17 (1): 27-37

[12.] Boulding, W. et al. (1993) 'A Dynamic Process Model of Service Quality: From Expectations to Behavioural Intentions'. Journal of Marketing Research, 30: 7-27

[13.] Bowen, D.E. and Lawler, E.E. (1992) 'The Empowerment of Service Workers: What, Why, How, and When'. Sloan Management Review, 33 (3): 31-39

[14.] Brannick, T. and Roche, W.K. (1997) Business Research Methods: Strategies, Techniques and Sources. Dublin: Oak Tree Press

[15.] Bryman, A and Bell, E (2007) Business Research Methods. New York: Oxford University

[16.] Bryman, A. and Bell, E. (2011) Business Research Methods. New York: Oxford University Press.

[17.] Cawley, A and Hynes, D. (2010) 'Evolving Mobile Communication Practices in Irish Teenagers'. Aslib Proceedings, 62 (1): 29-45

[18.] Cervellon, Marie-Cecile and Dube, Laurette (2002) 'Assessing the cross-cultural applicability of affective and cognitive components of attitude'. Journal of Cross-Cultural Psychology, 33: 346-357

[19.] Chang, T.Z. and Wildt, A.R. (1994) 'Price, product information, and purchase intention: an empirical study'. Journal of academy of marketing science, 22(1): 16-27

[20.] Claxton, C. S., \& Murrell, P. H. (1987) Learning styles. Washington, DC: George Washington University (ERIC)

[21.] Clemmer, E.C. and Schneider, B. (1996) 'Fair Service'. In Advances in Services Marketing and Management, 5

[22.] Coffield, F. J., Moseley, D. V., Hall, E., \& Ecclestone, K. (2004a). Learning styles and pedagogy in post-16 learning: A systematic and critical review. London:

[23.] ComReg, (2007) 'Newsletter'. July to September, (Internet). Available from: http://www.askcomreg.ie/_fileupload/publications/Winter2007.pdf

[24.] ComReg, (2010) 'Irish Communications Market: Key Data Report-Quarter 4'. (Internet). Available from: http://www.comreg.ie/_fileupload/publications/ComReg1121.pdf

[25.] ComReg, (Internet). Available from:

http://www.comreg.ie/_fileupload/publications/ComReg1121.pdf 
[26.] ComReg (Internet). Available from: http://www.comreg.ie/_fileupload/publications/ComReg1198.pdf

[27.] Cronin, J.J. and Taylor, S.A. (1992) 'Measuring service quality: a re-examination and extention'. Journal of marketing, 56: 55-68

[28.] Crosby, P.B. (1979) Quality is free. New York: McGraw Hill

[29.] Data Protection Commissioner of Ireland, (Internet). Available from: http://dataprotection.ie/docs/Home/4.htm

[30.] De Mooij, M. (2004) Consumer Behaviour and Culture: Consequences for Global Marketing and Advertising. California: Sage Publications, Inc

[31.] Deutsch, K. (1953) Nationalism and Social Communication: An inquiry into the Foundations of Nationality. Cambridge: MIT Press

[32.] De-Vaus, D.A. (2002) Surveys in Social Research. London: Routledge

[33.] Diaz-Loving, Rolando (1998) 'Contributions of Mexican ethno-psychology to the resolution of the etic-emic dilemma in personality'. Journal of Cross-Cultural Psychology, 29: 104-118

[34.] Dillman, D.A. (2000) Mail and Internet Surveys: The Tailored Design Method. New York: Wiley [35.] Dutta-Bergman, J.M. and Wells, W.D. (2002) 'The values and lifestyles of Idiocentrics and Allocentrics in an individual culture: A descriptive approach'. Journal of consumer psychology. 12(3): 231-242

[36.] Egan, J. (2004) Relationship Marketing: Exploring Relational Strategies in Marketing. Harlow, Pearson Education

[37.] Farley, T. (2007) 'The Cell-Phone Revolution', American Heritage of Invention \& Technology, 22 (3): 8-19

[38.] Fluhr, Z. and Nussbaum, E. (1973) 'Switching Plan for a Cellular Mobile Telephone System'. Transactions on Communications, 21: 1281

[39.] Foddy, W. (1994) Constructing Questions for Interviews and Questionnaires, Cambridge: Cambridge University Press

[40.] Folkes, V.S. (1988) 'Recent Attribution Research in Consumer Behaviour: A Review and New Directions'. Journal of Consumer Research, 14: 548-565

[41.] Fornell, C (1992) 'A National Customer Satisfaction Barometer: The Swedish Experience'. Journal of Marketing, 56: 6-21

[42.] Fournier, S. and Mick, D.G. (1999) 'Rediscovering Satisfaction'. Journal of Marketing, 63

[43.] Gabbott, M. and Hogg, G. (1988) Consumers and Services. New York: John Wiley and Sons Ltd

[44.] George, W.R. and Berry, L.L. (1981) 'Guidelines for the Advertising of Services' Business Horizons, 24 (May-June): 52-56

[45.] Ghobadian, A., Speller, S. and Jones, M. (1994) ' Service Quality Concepts and Models'. International Journal of. Quality \& Reliability Management, 11(9), 43-66.

[46.] Goulding, C. (2002) Grounded Theory: A Practical Guide for Management, Business and Market Researchers. London: Sage

[47.] Goulding, C. (2002) Grounded theory: A practical guide for management, business and marker researchers, London, Sage.

[48.] Gow, G.A. and Smith, R.K. (2006) Mobile and Wireless Communications: An Introduction. McGraw-Hill International, P 23

[49.] Gronroos, C. (1984) Strategic Management and Marketing in the Service Sector. Helsingfors, Sweden: Swedish School of Economics and Business Administration

[50.] Gronroos, C. (1990) Service Management and marketing. New York: Lexington Books

[51.] Grove, S. and Fisk, R. (1997) 'The Impact of Other Customers on Service Experiences: A Critical Incident Examination of "Getting Along"'. Journal of Retailing, 73 (1): 63-85

[52.] Grunert, Klaus G. et al., (1997) Food-related lifestyle: Development of a cross-culturally valid instrument for market surveillance, in values, lifestyles and psychographics. Mahwah, NJ: Lawrence Erlbaum, p. 343

[53.] Gwinner, K.P., Gremler, D.D. and Bitner, M. (1998) 'Relational Benefits in service industries: The Customer's perspective'. Journal of the Academy of Marketing science, 26 (2): 101-114 
South American Journal of Management

Special Edition 2016

[54.] Hande, Kimiloglu et al., (2010) 'Discovering behaviour segments in the mobile phone market'. Journal of consumer marketing, 27(5): 401-413

[55.] Haque, A., Khatibi, A. and Raquib, A. (2007) 'Consumer Perception and its Choice Mobile Telecom Service Provider in Malaysia'. Journal of International Business and Economics, 7 (2): 84

[56.] Hawk, T.F. and Shah, A.J. (2007) 'Using Learning Style Instruments to Enhance Student Learning'. Decision Sciences Journal of Innovative Education, 5(1)

[57.] Headley, D.E. and Miller, S.J. (1994) 'Measuring service quality and the relationship to future consumer behaviour'. 13(4): 32

[58.] Heron, J. (1996) Co-operative Inquiry: Research into the Human Condition. London: Sage

[59.] Hoffman, K.D. and Bateson, J.E.G. (2001) Essentials of Service Marketing. Hinsdale, IL: The Dryden Press.

[60.] Hofstede, G. (1980). Cultures consequences: International differences in work-related values. Beverly Hills, CA: Sage publications.

[61.] Honey, P. and Mumford, A. (1986) Manual of Learning styles. UK: Peter Honey publications

[62.] Honey, P. and Mumford, A. ( 1992) The manual of learning styles. Maidenhead: Peter Honey.

[63.] Hubbert, A.R. (1995) 'Customer Co-Creation of Service Outcomes: Effects of Locus of Causality Attributions'. Doctoral Dissertation, Arizona State University, Tempe, Arizona International Journal of Quality \& Reliability Management, 11(9): 43-66.

[64.] International Telecommunication Union (2005) 'ICT Statistics', URL (consulted 27 June 2012): http://www.itu.int/itu-d/ict/statistics/

[65.] International Telecommunication Union (2005) (Internet). Available from: http://www.itu.int/ITU-D/ict/statistics/at_glance/cellular05.pdf

[66.] International Telecommunication Union-ITU (2006), 'World Telecommunication/ICT indicators, (Internet). Available from:

http://www.caricomict4d.org/stats/2006/World\%20Telecommunication\%20ICT\%20Development\%20 Report $\% 202006 \% 20-\% 20 I T U . p d f$

[67.] Johnson, William C. and Sirikit, Anuchit (2002) 'Service Quality in the Thai Telecommunication Industry: A Tool for Achieving a Sustainable Competitive Advantage', Management Decision, 40 (7): 693-701.

[68.] Jung-Hwan, K. and Kim, C. (2010) 'E-service quality perceptions: a cross-cultural comparison of American and Korean consumers'. Journal of research in interactive marketing, 4(3): 257-275

[69.] Kagitcibasi, Cigdem (1997) 'Individualism and Collectivism'. Handbook of cross-cultural psychology, 3: p. 31

[70.] Kaplan, R. S. and Norton, D.P. (1991) The balanced score card: measures that drive performance. Boston: Harvard Business School Press

[71.] Katz, D. and Kahn, R.L. (1978) The Social Psychology of Organisations. New York: Wiley and Sons.

[72.] Katz, J.E. and Aakhus, M.A. (2002) Perpetual Contract: Mobile Communication, Private Talk, Public Performance. Cambridge: Cambridge University Press

[73.] Kelly, S.W., Skinner, S.J. and Donnelly, J.H. (1992) 'Organisational Socialisation of Service Customers'. Journal of Business research, 25 (2): 197-214

[74.] Knisely, G. (1979) 'Comparing Marketing Management in Package Goods and Service Organisations'. A series of interviews appearing in Advertising Age, January 15, February 19, and May 14

[75.] Kolb, D. (1984). Experiential learning: Experience as the source of learning and development. Englewood Cliffs, NJ: Prentice-Hall.

[76.] Kolb Learning Style (Internet) Available from: http://www.businessballs.com/kolblearningstyles.htm

[77.] Kollmann, Tobias ("The Price/Acceptance Function: Perspectives of a Pricing Policy in European Telecommunication Markets", European Journal of Innovation Management, 3 (1), 2000, 7-14.

[78.] Kotler, Philip (1994) Marketing management, Englewood Cliffs, NJ: Prentice Hall, p. 183-184

[79.] Kroeber, A.L. and Kluckhohn, F.R. (1952). Culture: a critical review of concepts and definitions. Cambridge, MA: Harvard University Press. 
[80.] Kumar, R. (2005) Methodology: A step by step guide for beginners, London: Sage Publications [81.] Lai, F. and Hutchinson, J. (2007) 'An empirical assessment and application of SERVEQUAL in mainland China's mobile communications industry'. International Journal of Quality \& Reliability management, 4(6): 50-60

[82.] Legg, D. and Baker, J. (1991) ‘Advertising Strategies for Service Firms’ In Services Marketing, 282-291

[83.] Levitt, Theodore (1976) 'The Industrialisation of Service'. Harvard Business review, 54: 63-74

[84.] Lofland, J., and Lofland, L. (1995) Analysing Social Settings: A Guide to Qualitative Observation and Analysis. Belmont, CA: Wadsworth.

[85.] Loudon, D.L. and Della Bitta, A.J. (1993) Consumer Behaviour: Concepts and Applications, Fourth Edition, Singapore, McGraw-Hill.

[85.] Malai, V. and Mark, S. (2005) 'Cultural impact on the relationship among perceived service quality'. Journal of international consumer marketing, 17(4): 7-39

[86.] Markus, H. R. and Kitayama, S. (1991) 'Culture and the self: Implications for cognition, emotion, and motivation'. Psychological Review, 98: p 6, 224-253.

[87.] McAdams, D. P.,\&Pals, J. L. (2006). 'Anewbig five: Fundamental principles for an integrative science of personality'. American Psychologist, 61(3), 204-217.

[88.] Melody, W.H. (2001) Telecom Reform Principles, Policies and Regulatory Practices. Technical University of Denmark: Lyngby

[89.] Minna, Pura. (2005) 'Linking perceived value and loyalty in location-based mobile services'. Managing Service Quality, 15(6): 509-538

[90.] Morris, T. and Wood, S. (1991) 'Testing the Survey Method: Continuity and Change in British Industrial Relations'. Work, Employment and Society. 5 (2): 259-282

[91.] Neji, R. (2009) 'User's perceived service quality of mobile communications: Experience from Ethiopia'. International journal of Quality and Reliability Management, 26(7): 699-711

[92.] Nikbin, D. et al., (2012) 'Perceived justice in service recovery and switching intentions: Evidence from Malaysian Mobile Telecommunication Industry'. Management Research Review, 35(4)

[93.] Office of the Director of Telecommunications Regulation, (2001) 'Media Release'. March 8th,(Internet). Available from: http://www.comreg.ie/_fileupload/publications/pres080301.pdf

[94.] Oliver, R.L. (1997) Satisfaction: A behavioural perspective on the consumer. New York: McGraw-Hill

[60.] Ostrom, A. and Iacobucci, D. (1995) 'Consumer Trade-Offs and the Evaluation of Services'. Journal of Marketing, 59: 17-28

[61.] Ouchi, W.G. and McGuire, M. (1975) 'A Conceptual Framework for the Design of Organisational Control Mechanisms'. Management Science, 25 (9): 833-848

[62.] Pantouvakis, A. (2010) 'The relative importance of service features in explaining customer satisfaction'. Managing Service Quality, 20 (4): 366-387

[63.] Parasuraman, A. Zeithaml, V.A. and Berry, L.L. (1988) 'SERVQUAL: a multi-item scale for measuring customer perceptions of service quality'. Journal of Retailing, 64 Spring : 12-40

[64.] Parasuraman, A. Zeithaml, V.A. and Berry, L.L. (1994) 'Reassessment of expectations as a comparison standard in measuring service quality-implications for further research'. Journal of Marketing, 58 (1): 111-124

[65.] Parasuraman, A., Zeithaml, V.A., and Berry, L. (1990) Delivering quality service: Balancing customer perceptions and expectations. New York: The free press

[66.] Reichheld, F. and Sasser, E (1990) 'Zero Defections: Quality Comes to Services'. Harvard Business Review, 68: 106

[67.] Remenyi, D., Williams, B., Money, A. and Swartz, E. (1998) Doing Research in Business and Management: An Introduction to Process and Method. London: Sage

[68.] Rice, R.E. and Katz, J.E. (2003) 'Comparing Internet and Mobile Phone Usage: Digital Divides of Usage, Adoption and Dropouts'. Telecommunications Policy, 27: 597-623

[69.] Rizzo, J., House, R.J. and Lirtzman, S.I. (1970) 'Role Conflict and Ambiguity in Complex Organisations'. Administrative Science Quarterly, 15 (2): 150-163 
South American Journal of Management

Special Edition 2016

[70.] RNCOS (2008) 'Global mobile phone penetration to reach 50\% in 2008'. RNCOS industry research solutions. (Internet), Available from: www.rncos.com/Blog/2008/05/Global-Mobile

[71.] Roach, G. (2009) 'Consumer perceptions of mobile phone marketing: a direct marketing innovation'. Direct Marketing: An International Journal, 32 (2): 124-138

[72.] Robson, C. (2002) Real World Research. Oxford, Blackwell

[73.] Rockeach, M. (1973) The nature of human values. New York: Free Press, p.5

[74.] Roland, A. (1988) In search of self in India and Japan. Princeton, NJ: Princeton University Press

[75.] Santouridis, I. and Trivellas, P. (2010) 'Investigating the impact of service quality and customer satisfaction on customer loyalty in mobile telephony in Greece'. The TQM Journal, 22(3)

[76.] Saunders, M. et al., (2007) Research Methods for Business Students. London: Prentice Hall

[77.] Schneider, B. and Bowen, D. (1985) 'Employee and Customer Perceptions of Service in Banks: Replication and Extension'. Journal of Applied Psychology, 70 (3): 423-433

[78.] Schneider, B. and Bowen, D.E. (1993) 'The Service Organisation: Human Resources Management is Crucial'. Organisational Dynamics, 21 (4): 39-52

[79.] Sekaran, Uma (2003) Research Methods for Business: A skill building approach. United States of America: John Wiley \& Sons, Inc

[80.] Serwer, A.E. (1995) 'Trouble in Franchise Nation'. Fortune, (March 6): 115-118

[81.] Shostack, G.L. (1992) 'Understanding Services Through Blueprinting.' In Advances in Services Marketing, and Management: Research and Practice, 1

[82.] Singelis, Theodore M. (2000) 'Some thoughts on the future of cross-cultural social psychology'. Journal of cross-cultural Psychology, 31: 76-91

[83.] Solomon, M. et al., (1999) Consumer behaviour: A European perspective. Harlow, Essex, UK: Pearson Education, p. 8

[84.] Steenkamp, J.B.E.M. (1989) Product Quality: An Investigation into The Concept and how it is Perceived by Consumers. Assen/Maastricht, The Netherlands: Van Gorcum

[85.] Sutherland, E. (2007) 'The regulation of the quality of service in mobile networks'. Info, 9 (6): $17-34$

[86.] Szwarc, P. (2005) Researching customer satisfaction \& loyalty: How to find out what people really think. London: Kogan Page.

[87.] Tai, Susan H.C. and Tam, Jackie L.M. (1996) 'A comparative study of Chinese consumers in Asian markets: a lifestyle analysis'. Journal of International Consumer Marketing, 9: 25-42

[88.] Tashakkori, A. and Teddlie, C. (1998) Mixed Methodology: Combining Qualitative and Quantitative Approaches. Thousand Oaks, CA: Sage

[89.] Tax, S.S. and Brown, S.W. (1998) 'Recovering and Learning from Service Failure'. Sloan Management Review, 40 (1): 75-88

[90.] Wang, Y. and Hing-Po Lo. (2002) 'Service quality, customer satisfaction and behaviour intentions: Evidence from China's telecommunications industry'. Info, 4 (6): 50-60

[91.] Webster Jr, F.E. (1992) 'The Changing Role of Marketing in the Corporation'. Journal of Marketing, 56: 1-17

[92.] Wilson-Jeanselme, M. (2001) 'Grocery retailing on the internet: The leaky bucket theory'. Oxford Institute of Retail Management. European Retail Digest, issue 30: p9

[93.] Zeithaml, V. and Bitner, M.J. (2003) Services Marketing: Integrating Customer Focus Across the Firm. Burr Ridge, Ill: Irwin McGraw-Hill

[94.] Zeithaml, V.A. and Parasuraman, A. (2004) Service Quality. United States of America: Marketing Science Institute

[95.] Zeithaml, V.A. et al., (2009) Services Marketing: Integrating customer focus across the firm. New York: McGraw Hill

[96.] Zeithaml, V.A., Berry, L.L. and Parasuraman, A. (1988) 'Communication and Control Processes in the Delivery of Service Quality'. Journal of Marketing, 52 (2): 35-48 